\title{
The time evolution of aerosol size distribution over the Mexico City plateau
}

\author{
L. I. Kleinman ${ }^{1}$, S. R. Springston ${ }^{1}$, J. Wang ${ }^{1}$, P. H. Daum ${ }^{1}$, Y.-N. Lee ${ }^{1}$, L. J. Nunnermacker ${ }^{1}$, G. I. Senum ${ }^{1}$, \\ J. Weinstein-Lloyd ${ }^{2}$, M. L. Alexander ${ }^{3}$, J. Hubbe ${ }^{3}$, J. Ortega ${ }^{3}$, R. A. Zaveri ${ }^{3}$, M. R. Canagaratna ${ }^{4}$, and J. Jayne ${ }^{4}$ \\ ${ }^{1}$ Brookhaven National Laboratory, Upton, New York, USA \\ ${ }^{2}$ SUNY, Old Westbury, NY, USA \\ ${ }^{3}$ Pacific Northwest National Laboratory, Richland, WA, USA \\ ${ }^{4}$ Aerodyne Research Inc., Billerica, MA, USA
}

Received: 31 October 2008 - Published in Atmos. Chem. Phys. Discuss.: 16 January 2009

Revised: 6 May 2009 - Accepted: 4 June 2009 - Published: 3 July 2009

\begin{abstract}
As part of the MILAGRO field campaign, the DOE G-1 aircraft was used to make measurements over and downwind of Mexico City with the objective of determining growth characteristics of aerosols from a megacity urban source. This study focuses on number concentration and size distributions. It is found that a 5 -fold increase in aerosol volume is accompanied by about a 5-fold increase in accumulation mode number concentration. There is growth in aerosol volume because there are more accumulation mode particles, not because of an increase in the average size of accumulation particles. Condensation and volume growth laws were examined to see whether either is consistent with observations. Condensation calculations show that the growth of Aitken mode particles into the accumulation mode size range gives the required increase in number concentration. There are minimal changes in the accumulation mode size distribution with age, consistent with observations. Volume-growth in contrast yields a population of large particles, distinctly different from what is observed. Detailed model calculations are required to translate our observations into specific information on the volatility and properties of secondary organic aerosol.
\end{abstract}

\section{Introduction}

The MILAGRO field campaign, conducted in March, 2006 (Molina et al., 2008) was designed so that air masses carrying

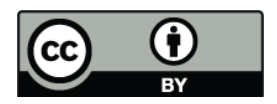

Correspondence to: L. I. Kleinman (kleinman@bnl.gov) emissions from Mexico City and other sources could be sampled at varying downwind distances. Atmospheric processing time could then be determined from wind speed, dispersion models, or Lagrangian markers (Fast and Zhong, 1998; de Foy et al., 2006; Doran et al., 2007; DeCarlo et al., 2008; Zaveri et al., 2008). Atmospheric processing times could also be determined using the ratio of compounds that react at different rates or by changes in aerosol oxidation state (Herndon et al., 2008; DeCarlo et al., 2008). These methods provide information on the evolution of trace gas and aerosols emitted from Mexico City over time scales ranging from less than $1 \mathrm{~h}$ to several days.

In this study we present results from the DOE G-1 aircraft on the size distribution of aerosol particles and their time evolution over the Mexico City plateau. Our methodology closely follows that used to determine changes in aerosol composition (Kleinman et al., 2008). As in that study, which will be referred to as K2008, a set of selection criteria consisting of chemical composition, location, and turbulence are used to restrict the G-1 data set to boundary layer observations for which the primary emission input is from urban sources. Atmospheric processing time is estimated by the photochemical age method, using the ratio of $\mathrm{NO}_{\mathrm{x}}$ to $\mathrm{NO}_{\mathrm{y}}$. Aerosol properties are normalized for dilution by using $\mathrm{CO}$ as a tracer of the urban plume. Because morning and afternoon size distributions are different, most prominently in the Aitken mode, results are presented separately for the AM and PM.

The time dependence of an aerosol size distribution contains information on the mechanism by which aerosol mass is produced (e.g. McMurry et al., 1981; Brock et al., 2002; Wang et al., 2006). Formation of aerosol sulfate from $\mathrm{SO}_{2}$

Published by Copernicus Publications on behalf of the European Geosciences Union. 
in power plant plumes is the most studied system. In one mechanism, gas-phase reaction of $\mathrm{SO}_{2}$ with $\mathrm{OH}$ produces $\mathrm{H}_{2} \mathrm{SO}_{4}$. Because $\mathrm{H}_{2} \mathrm{SO}_{4}$ is nearly non-volatile, its fate once it diffuses to an aerosol particle is irreversible uptake. Diffusion to small particles is favored over diffusion to large particles, the result being a "condensation growth law" in which $d D_{p} / d t \sim 1 / D_{p}$ where $D_{p}$ is particle diameter and a continuum regime is assumed. $\mathrm{H}_{2} \mathrm{SO}_{4}$ can also be formed by aqueous-phase reactions, usually in cloud droplets, which subsequently form an aerosol particle upon evaporation. In that case the formation rate of $\mathrm{H}_{2} \mathrm{SO}_{4}$ is proportional to reaction volume, yielding a "volume growth law" $d D_{p} / d t \sim D_{p}$. In the diffusion controlled case, small particles grow in diameter faster than large ones. The opposite is true for volume controlled growth. Whether aerosol mass is distributed over small or large particles has multiple climate impacts deriving from cloud albedo, cloud lifetime, and direct radiative effects (Twomey, 1974; Albrecht, 1986; Schwartz, 1996).

In contrast to better understood inorganic systems, Mexico City aerosol sampled from the G-1 was largely organic. Of the non-refractory aerosol species measured with a c-ToF AMS (compact - Time of Flight Aerosol Mass Spectrometer), organics constitute more than $50 \%$ of the mass and more than $60 \%$ of the volume. Absorption - partitioning theory has been successfully used to describe smog chamber experiments on the formation of secondary organic aerosol (SOA) from VOC precursors (Odum et al., 1996). Size distributions in the absorptive - partitioning model follow from equilibrium relations that depend on chemical and physical properties of the aerosol constituents. Because organic systems in the ambient atmosphere are variable and complex, there are no general solutions for SOA growth laws. Further complicating the derivation of SOA growth laws are major uncertainties as to VOC precursors, kinetics of gas to particle transfer, composition and properties of condensed phase(s), and aerosol-phase reactions (Kroll et al., 2007; Robinson et al., 2007; Kroll and Seinfeld, 2008). Also, as Bowman et al. (1997) caution, aerosols are not necessarily in equilibrium and, "the resulting size distribution of the condensed semi-volatile product cannot be uniquely determined without accounting for size-dependent rates of mass transfer between the gas and aerosol phase".

Using the methods of $\mathrm{K} 2008$, we calculate the number of accumulation mode aerosol particles above background (determined by PCASP and DMA) normalized to abovebackground CO concentration (also referred to as "per CO") as a function of photochemical age. The age dependence of number concentration is compared with the age dependence of volume (determined by PCASP, DMA, and AMS) to determine whether the observed 5 fold increase in aerosol volume per $\mathrm{CO}$ is caused by more particles or larger particles. It is found that the aerosol volume increase is due primarily to increased numbers of accumulation mode particles. A qualitative explanation is sought by examining simplified versions of condensation and volume growth mechanisms.

\section{Experimental}

The reader is referred to K2008 for 1) a description of the instruments used to define an urban data set, account for urban plume dilution, and calculate photochemical age; 2) the determination of aerosol volume from PCASP and DMA measurements; and 3) a description of c-ToF AMS concentration measurements including the determination of a collection efficiency by a volume to volume comparison between the AMS and the PCASP or DMA. The focus of K2008 was on aerosol mass and composition. Here we are also interested in particle number concentration and number and volume size distributions $\left(d \mathrm{~N} / d \log D_{p}\right.$ and $\left.d V / d \log D_{p}\right)$. The size ranges covered by the DMA and PCASP are 15-440 nm and $100-2800 \mathrm{~nm}$, respectively. Data will be presented from either or both of these instruments according to the diameter range of interest.

A description of the c-ToF AMS is given by Drewnick et al. (2005). On the G-1, the AMS operated on a 13 s cycle, split evenly between mass spectrum (MS) and time of flight (ToF) mode. In MS mode, aerosol concentrations are quantified without regard to particle size. Volume and mass concentrations used in this study are determined from the MS mode. In ToF mode, the AMS yields the mass of non-refractory aerosol constituents as a function of vacuum aerodynamic diameter, $D_{\text {va }}$. A chopper with a narrow slit is used to create and time a narrow pulse of aerosol sample, with the result that the duty cycle of the instrument for making size resolved mass measurements is only $1 \%$. As a consequence, size distributions are noisy and many have to be averaged together to give a useful signal. In keeping with the approach outlined in K2008, size distributions are averaged over bins defined by photochemical age. For spherical particles, as assumed in this study, vacuum aerodynamic diameter measured by the AMS is related to geometric diameter, $D_{p}$, by

$D_{\mathrm{va}}=\rho / \rho_{0} D_{p}$

where $\rho$ and $\rho_{0}$ are densities of aerosol and water, respectively. $\rho / \rho_{0}$ has a typical value of 1.5 based on measured composition and densities of 1.2 and 1.77 for organic and inorganic species. AMS size distributions will be shown between 50 and $500 \mathrm{~nm}\left(D_{p}\right)$, the upper bound corresponding to approximately $60 \%$ transmission efficiency of the AMS aerodynamic lens (Liu et al., 2007).

For this study, the data set is obtained from the same 8 flights used in K2008. Sampling was performed over Mexico City and to the west and south where relatively concentrated, freshly emitted pollutants were encountered. More dilute and aged air masses were encountered on east-west transects that went over the T1 and T2 surface sites, located 35 and $70 \mathrm{~km}$ to the NE of the T0 urban site. Flight tracks and surface site locations are shown in K2008. Further information on chemical environments is in Nunnermacker et al. (2008).

Data presented in this study have been merged to a $10 \mathrm{~s}$ time base. All observations have time constants comparable 
to or faster than $10 \mathrm{~s}$, with the exception of the DMA which takes approximately $1 \mathrm{~min}$ to scan over its size range, during which time the G-1 travels $10 \mathrm{~km}$. In assigning a DMA observation to a $10 \mathrm{~s}$ interval, it is assumed that the DMA size distributions accumulated over $1 \mathrm{~min}$, are constant over that minute, an obvious approximation in non-homogeneous air masses. The alternative of merging to the DMA time base is not any more appealing because high frequency information contained in the relation between AMS aerosol and trace gas concentrations is lost. Independent of the time base selected, DMA size distributions in non-homogeneous air masses can be distorted if, for example, small particles are measured in clean air at the start of a scan and large particles in polluted air at the end of a scan. A similar effect occurs with the proton transfer mass spectrometer (PTR-MS), but is less serious because the scan time is $\sim 15 \mathrm{~s}$. Based on the standard deviation of 6 consecutive $10 \mathrm{~s}$ average PCASP number concentrations, we estimate that air mass inhomogeniety contributes an average $1 \sigma$ uncertainty of $14 \%$ to a 1 min DMA measurement.

As in K2008, trace gas concentrations are given in ppb or ppm by volume. Aerosol concentrations and volumes are given at standard conditions, defined here as $20^{\circ} \mathrm{C}$ and 1 atmosphere pressure. Local times, equal to UTC $-6 \mathrm{~h}$, are used in this study. Data are archived at ftp://ftp.asd.bnl.gov/ pub/ASP\%20Field\%20Programs/2006MAXMex/. On the ftp site, aerosol properties are reported at ambient conditions and times are in UTC.

\section{Data analysis method}

Common to the analysis in K2008 and this study are 1) a set of screening criteria to identify air masses that are primarily affected by urban emissions, 2) the quantification of atmospheric processing time by the photochemical age ratio, $-\log _{10}\left(\mathrm{NO}_{\mathrm{x}} / \mathrm{NO}_{\mathrm{y}}\right)$, and 3$)$ the use of $\mathrm{CO}$ as a conservative tracer of urban emissions to account for dilution. A brief summary of these procedures is given here, followed by material that is specific to this study.

Selection criteria given in Table 4 of K2008 are applied to the data set so as to focus on urban emissions. Longitude and turbulent energy dissipation rate are used to restrict the data set to the boundary layer over the Mexico City plateau. It is required that the $\mathrm{CO} / \mathrm{NO}_{\mathrm{y}}$ ratio be near that observed in plumes which unmistakably have an urban origin, the condition being that $15<(\mathrm{CO}-100) / \mathrm{NO}_{\mathrm{y}}<25$. The influence of forest fires is minimized, but not totally eliminated, according to the $\mathrm{CH}_{3} \mathrm{CN} / \mathrm{CO}$ ratio. For pollutants to be classified as urban $\mathrm{CH}_{3} \mathrm{CN}(\mathrm{ppb})<0.2+0.4 \times 10^{-3} \mathrm{CO}(\mathrm{ppb})$. Industrial sources, in particular plumes from the Tula industrial complex, are removed by constraints on $\mathrm{SO}_{2}$ - and by the $\mathrm{CO} / \mathrm{NO}_{\mathrm{y}}$ ratio used to describe urban emissions. Application of these condition yields an "urban data set".
Photochemical age defined as $-\log _{10}\left(\mathrm{NO}_{\mathrm{x}} / \mathrm{NO}_{\mathrm{y}}\right)$ is an independent variable describing the extent of atmospheric processing. DeCarlo et al. (2007) have shown that the $\mathrm{NO}_{\mathrm{x}} / \mathrm{NO}_{\mathrm{y}}$ clock in Mexico City is correlated with age-related changes to aerosol $\mathrm{O}$ to $\mathrm{C}$ ratios. Observations in the Tokyo urban plume indicate that $\mathrm{NO}_{\mathrm{x}} / \mathrm{NO}_{\mathrm{y}}$ yields a photochemical age similar to that obtained from an alkyl nitrate - parent alkane ratio (Miyakawa et al., 2008). In K2008, samples with "Age" between 0 and 1 were divided into 10 age bins each 0.1 units wide. Over this range, $\mathrm{NO}_{\mathrm{x}} / \mathrm{NO}_{\mathrm{y}}$ varies from $100 \%$ to $10 \%$. Older samples were present, but not in sufficient number to give statistically meaningful results. The age range from 0.1 to 1 qualitatively corresponds to $1 / 2$ to 1 day of atmospheric processing. As boundary layer accumulation mode aerosol have a lifetime of order 1 week (Jaenicke, 1980), number and volume concentration should not be significantly impacted by physical loss over our limited sampling age range.

As the urban plume is advected away from its source region it dilutes due to the mixing-in of "background air". In order to account for dilution, aerosol properties (e.g. $\mathrm{X}=$ aerosol mass) are expressed per ppm $\mathrm{CO}$, where $\mathrm{CO}$ is taken as a conservative tracer of urban emissions. Both $\mathrm{X}$ and $\mathrm{CO}$ in this context refer to concentrations from urban sources in excess of background values. The air over the Mexico City plateau is filled with a dilute but variable mixture of pollutants making it difficult to identify background concentrations. Instead of subtracting background values from $\mathrm{X}$ and $\mathrm{CO}$ as was done in Kleinman et al. (2007), the ratio X/CO is determined as the slope of a reduced major axis regression of $\mathrm{X}$ vs. CO. Regressions are done for each age bin. In order to describe aerosol growth with age, we employ measures of the fractional and absolute change of $\mathrm{X} / \mathrm{CO}$. The fractional change, $\mathrm{G}$, is the ratio of $\mathrm{X} / \mathrm{CO}$ at an age of 0.9 to its value at an age of 0.1 (limits of 0.084 and 0.94 were used in K2008). Values of $\mathrm{X} / \mathrm{CO}$ at these ages are determined as points on a linear regression of $\mathrm{X} / \mathrm{CO}$ vs. age. An absolute increase in $\mathrm{X} / \mathrm{CO}$, denoted by $\Delta$ is defined as the difference in $\mathrm{X} / \mathrm{CO}$ between ages of 0.9 and 0.1 .

Changes in the regression slope as a function of photochemical age lead to the result in K2008 that total nonrefractory aerosol and organic aerosol increase by factors of 5 and 7 as an air mass ages. In this study the dependence of the number of accumulation mode aerosol particles on photochemical age is determined with the same selection criteria and regression methodology used for aerosol volume and mass. However, the regression methodology does not carry over to the examination of the age dependence of size distributions. Instead, size distributions have been averaged over specific age bins, yielding a composite result for plume plus background aerosol.

Time of day effects on aerosol size distributions were investigated by comparing data collected before (AM) and after (PM) noon. Average measurement times were 11:14 and 14:31. AM and PM samples are $32 \%$ and $68 \%$ of the total, respectively. To improve sampling statistics, particularly for 

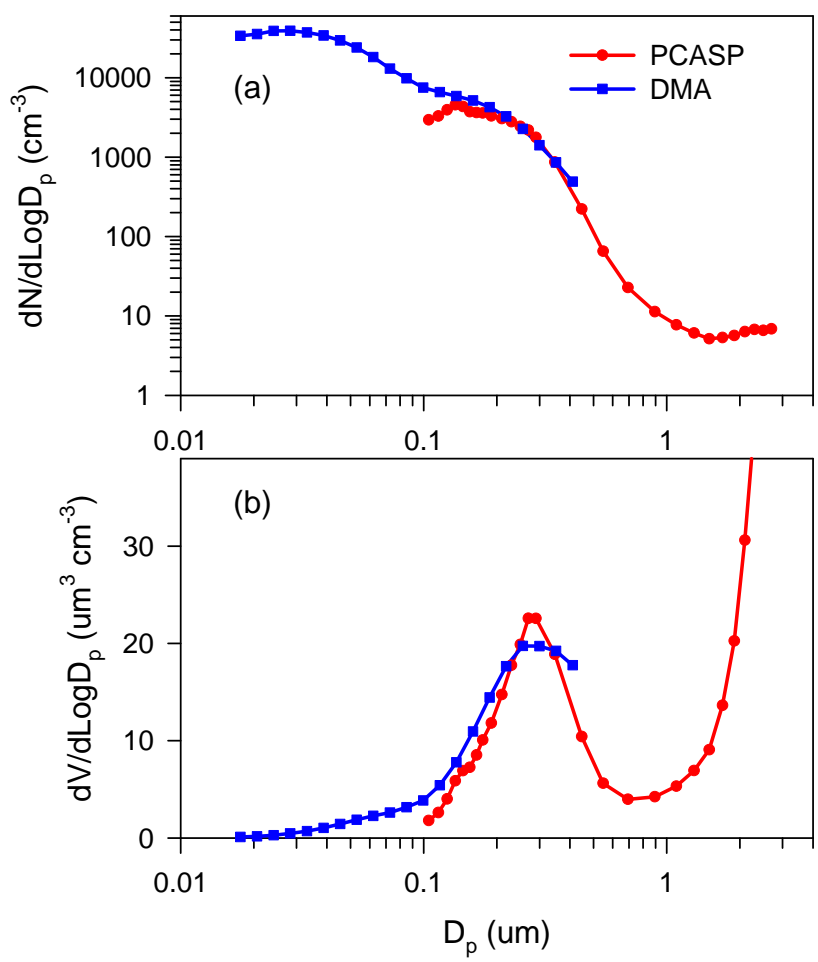

Fig. 1. (a) Aerosol number and (b) volume size distribution measured by the PCASP and DMA for the urban data set. Symbols indicate the geometric mean of size-bin boundaries.

low age PM samples and older AM samples, data are divided into 0.2 age unit bins when examining $\mathrm{AM}$ and PM samples separately. The $18 \mathrm{~km}$ wide, high $\mathrm{CO}$ plume that was noted as having an anomalous Organic/CO ratio has been removed because of its disproportionate influence on PM samples (K2008).

\section{Results}

\subsection{Mode structure}

Over the $15 \mathrm{~nm}$ to $3 \mu \mathrm{m}$ size range covered by the DMA and PCASP, aerosol size distributions exhibit 3 to 4 modes. Number and volume size distributions, averaged over the entire urban data set, (Fig. 1) can be decomposed into an Aitken mode, accumulation mode, and coarse particle mode. Not evident in Fig. 1a are the instances in which the DMA number distribution has a large peak at its lower size limit, indicating a 4th mode, either associated with recent nucleation events or fresh emissions of ultrafine particles. The coarse mode, only partially captured by the PCASP, is present in most size distributions but is highly variable and is not correlated with anthropogenic tracers such as CO. Dust events contributing to this mode were visually observed from the G-1 and detected by the NASA airborne High Spectral Res-
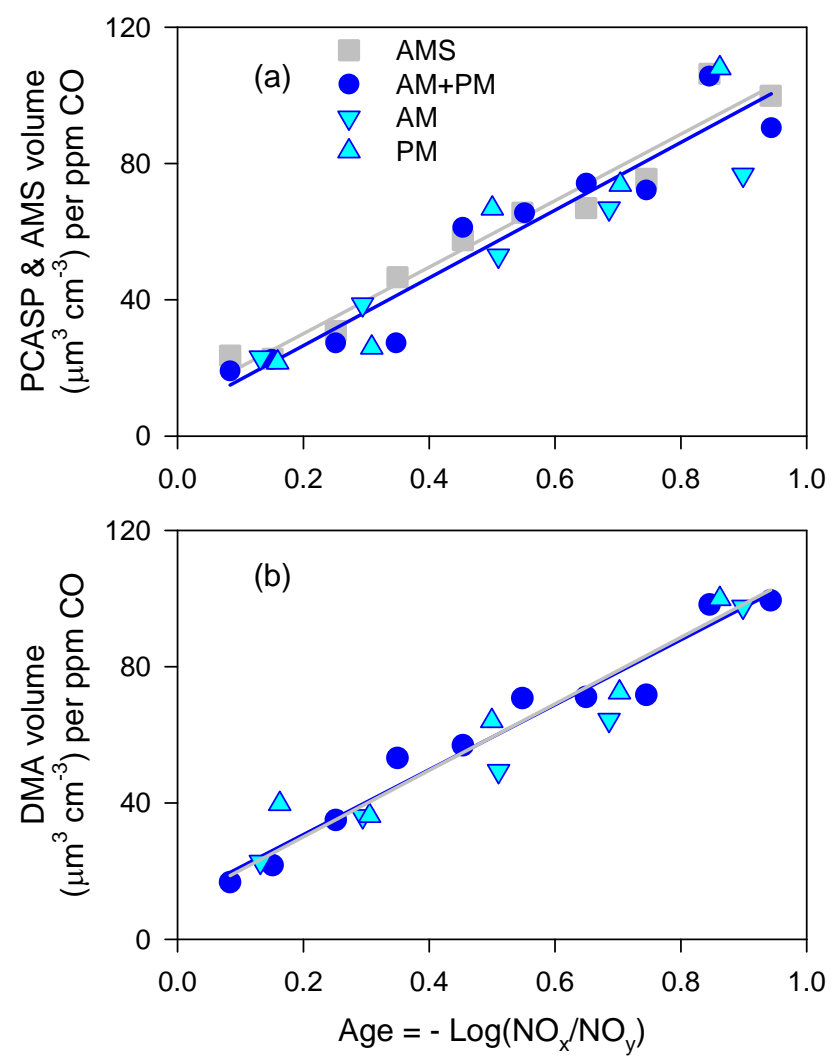

Fig. 2. Dependence of aerosol volume (in excess of background) per ppm of urban CO (in excess of background) on photochemical age. Each data point is the reduced major axis slope from a linear regression of aerosol volume vs. CO. (a) PCASP and AMS volume per $\mathrm{CO}$ as a function of photochemical age. Straight lines are linear least squares fit to the AM+PM data points for PCASP and AMS volumes. Slopes of least squares fit to PCASP data are 99, 70 , and $122 \mu \mathrm{m}^{3} \mathrm{~cm}^{-3}$ per ppm CO for $\mathrm{AM}+\mathrm{PM}, \mathrm{AM}$, and $\mathrm{PM}$, respectively. (b) DMA volume per $\mathrm{CO}$ as a function of photochemical age. Straight lines are linear least squares fit to the AM+PM data points for DMA volume and for comparison the AMS linear fit shown in panel a which partially obscures the DMA fit. Slopes of least squares fit to DMA data are 95,93 , and $88 \mu \mathrm{m}^{3} \mathrm{~cm}^{-3}$ per ppm CO for AM + PM, AM, and PM, respectively.

olution Lidar (Rogers et al., 2009). As our main interest is in anthropogenic urban pollutants which are expected to be in the sub micrometer size range, the coarse mode aerosol will not be discussed further. There is reasonable agreement between DMA and PCASP measurements for particle number and volume integrated over the $100-440 \mathrm{~nm}$ overlap region. A comparison of the size distributions shows differences which are likely due to uncertainties within the PCASP in translating a scattering signal into a geometric diameter.

Although modes overlap and have variable positions, nominal diameters of the Aitken and accumulation modes are often taken to be $15 \mathrm{~nm}-0.1 \mu \mathrm{m}$ and $0.1 \mu \mathrm{m}-1 \mu \mathrm{m}$, respectively. Somewhat different definitions are used here in order 

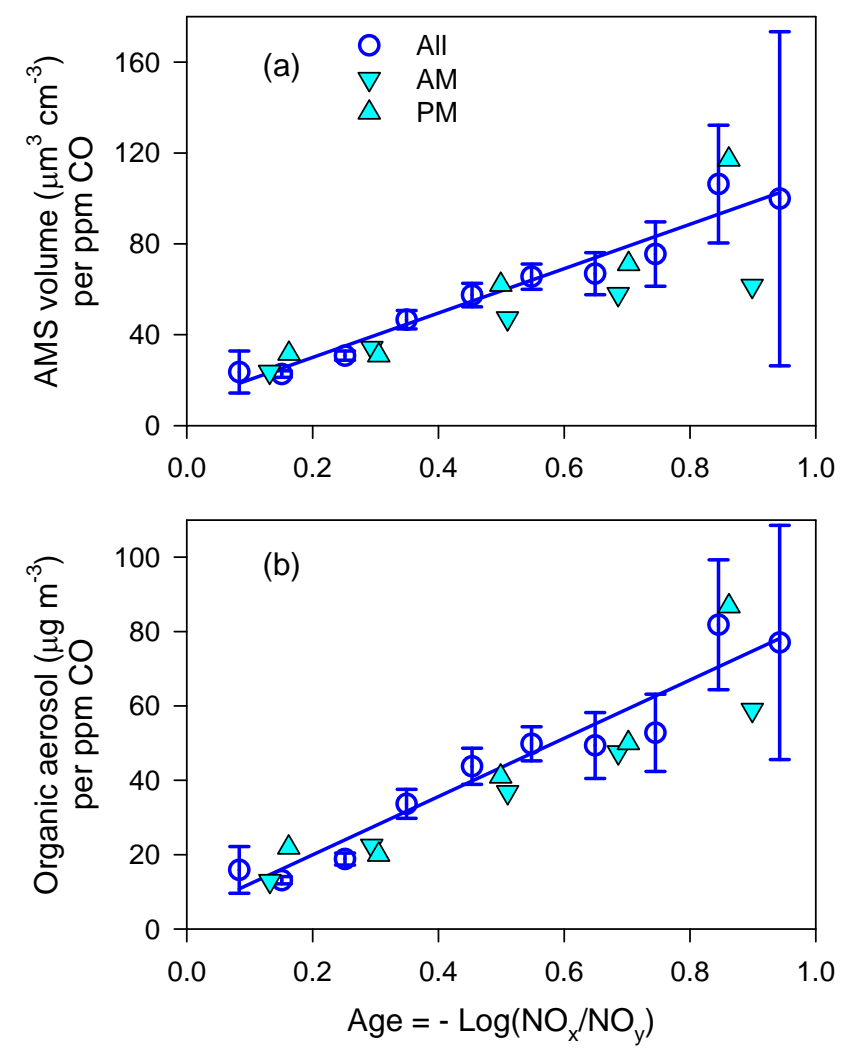

Fig. 3. Data points are slopes from reduced major axis regression of (a) AMS volume and (b) Organic aerosol concentration per CO plotted as a function of photochemical age. Error bars are $2 \sigma$, calculated from $\chi^{2}$ of the regressions (Press et al., 1986). Graphs show linear least squares fit to the AM+PM (All) data points for (a) AMS volume and (b) Organic concentration. AMS "All" data are identical to those shown in Fig. 2. Slopes of least squares fit to AMS volume in (a) are 98, 51, and $117 \mu \mathrm{m}^{-3} \mathrm{~cm}^{-3}$ per ppm CO for $\mathrm{AM}+\mathrm{PM}, \mathrm{AM}$, and PM, respectively. Slopes of least squares fit to organic concentration in (b) are 78,61, and $89 \mu \mathrm{g} \mathrm{cm}^{-3}$ per ppm $\mathrm{CO}$ for $\mathrm{AM}+\mathrm{PM}, \mathrm{AM}$, and $\mathrm{PM}$, respectively.

to accommodate the operating characteristics of the AMS, PCASP, and DMA. Size resolution from the AMS can only be accomplished for long integration times. As there is no practical way of subtracting the contributions of particles smaller than $0.1 \mu \mathrm{m}$ (averaging 15\% of mass), aerosol mass determined from the AMS is specified as being all in the accumulation mode. For comparison purposes, DMA volume is defined to include particles with $D_{p}<0.1 \mu \mathrm{m}$. PCASP volume is likewise defined to include particles with $D_{p}<0.1 \mu \mathrm{m}$ by adding the measured DMA volume of sub $0.1 \mu \mathrm{m}$ particles. The upper size limit of what we are calling the accumulation mode is $\sim 0.6 \mu \mathrm{m}$ for the AMS as determined by the aerodynamic lens, $440 \mu \mathrm{m}$ for the DMA as dictated by instrument factors, and $1 \mu \mathrm{m}$ for the PCASP. Although these upper limits don't coincide, Fig. 1 shows that they come close to capturing the measured accumulation mode volume.
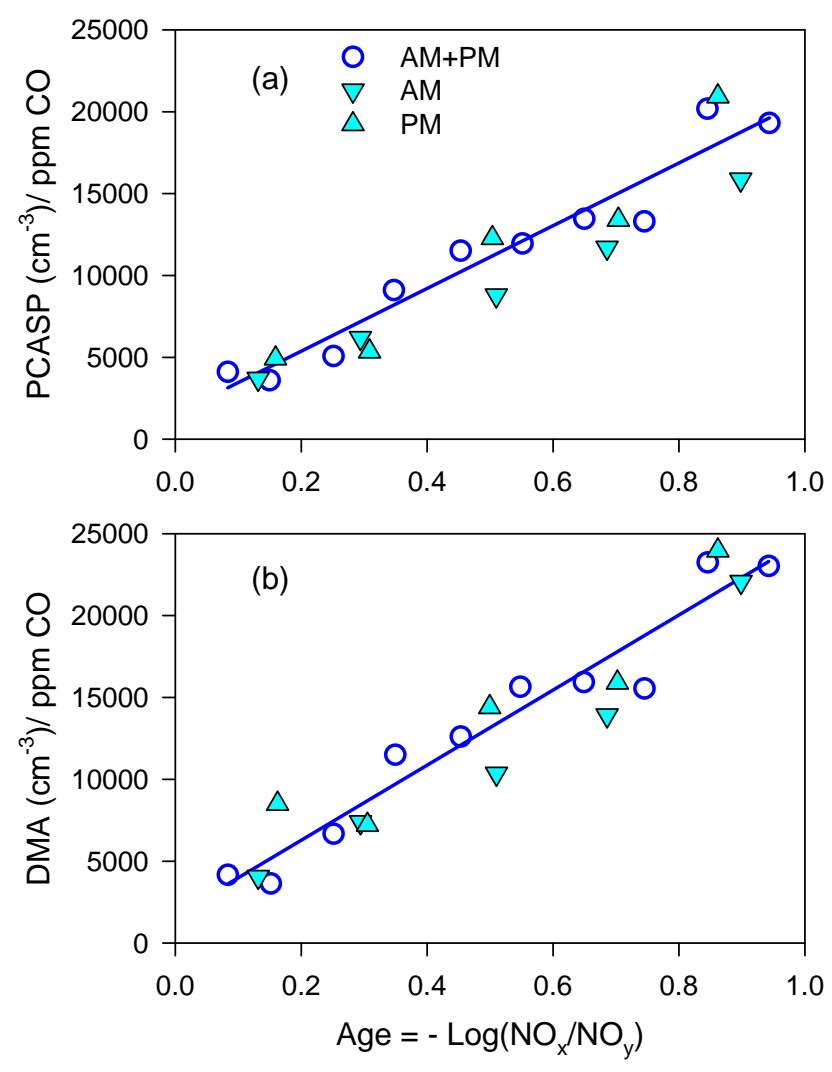

Fig. 4. Data points are slopes of reduced major axis regression of (a) PCASP and (b) DMA number concentration plotted as a function of photochemical age. Same format as Fig. 2. Slopes of least squares fit to PCASP number concentration in (a) are 19200, 15 500, and $22200 \mathrm{~cm}^{-3}$ per ppm CO for AM + PM, AM, and PM, respectively. Slopes of least squares fit to DMA number concentration in (b) are 22900,22200 , and $22200 \mathrm{~cm}^{-3}$ per ppm CO for AM+PM, AM, and PM, respectively.

DMA and PCASP accumulation mode number concentration are defined as extending from $0.1 \mu \mathrm{m}$ to 0.44 or $1.0 \mu \mathrm{m}$, respectively - the difference between these limits not being significant because of the rapid drop off of number with size.

\subsection{Dependence of aerosol number and mass on photo- chemical age}

We compare the change in aerosol volume during aging to changes in aerosol number concentration for the purpose of understanding the mechanism of aerosol growth. This comparison is carried out for the accumulation mode as defined in the preceding section. Thus, the much larger number of Aitken mode particles indicated in Fig. 1a will not dominate the comparison.

The dependence of aerosol volume, number concentration, and organic mass on photochemical age is shown in Figs. 24. Volumes have been derived from AMS, PCASP, and DMA observations; number concentrations from the PCASP and 
Table 1. Change in aerosol volume and number concentration due to a change in photochemical age, $-\log \left(\mathrm{NO}_{\mathrm{x}} / \mathrm{NO}_{\mathrm{y}}\right)$, from 0.1 to 0.9 .

\begin{tabular}{lll}
\hline Quantity $^{1}$ & Fractional increase $(\mathrm{G})$ & Absolute change $(\Delta)$ \\
\hline PCASP volume & 5.8 & $79\left(\mu \mathrm{m}^{3} \mathrm{~cm}^{-3}\right)$ \\
DMA volume & 4.6 & $76\left(\mu \mathrm{m}^{3} \mathrm{~cm}^{-3}\right)$ \\
AMS volume & 4.9 & $78\left(\mu \mathrm{m}^{3} \mathrm{~cm}^{-3}\right)$ \\
PCASP number & 5.4 & $15300\left(\mathrm{~cm}^{-3}\right)$ \\
DMA number & 5.6 & $18300\left(\mathrm{~cm}^{-3}\right)$ \\
\hline
\end{tabular}

${ }^{1}$ per ppm CO above background

DMA; and organic mass from the AMS. Results are presented for the entire urban data set as well as AM and PM portions. Data points in Figs. 2-4 are determined as linear regression slopes, illustrated in Fig. 5 for the case of PCASP number concentration vs. CO (compare mass regressions in Supplemental material of K2008). As intercepts are not fixed, regression slopes yield the number of accumulation mode particles associated with a ppm of urban $\mathrm{CO}$, a quantity that does not depend on a priori estimates of background concentrations.

Figures 2 and 3 a show aerosol volume as a function of photochemical age. There is excellent agreement for the volume increase between Age $=0.1$ and Age $=0.9$ for the $\mathrm{AM}+\mathrm{PM}$ measurements from the DMA, PCASP, and AMS: 76, 79, and $78 \mu \mathrm{m}^{3} \mathrm{~cm}^{-3}$, respectively. These absolute changes represent an approximately 5 -fold increase in volume, in line with the mass increase reported in K2008 for AMS measurements of total non-refractory aerosol mass. Organic aerosol concentration, shown in Fig. 3b, increases 6.4 fold $\left(62 \mu \mathrm{g} \mathrm{m}^{-3}\right)$ over the 0.1 to 0.9 size range.

According to the PCASP and AMS observations in Figs. 2a and 3a, there is more aerosol growth in the PM than AM, while DMA volumes in Fig. 2b show a slightly greater increase in the AM. Contributing factors could be diurnal variations in meteorology, emission rates, or new particle formation. As will be shown below there are differences between AM and PM aerosol size distributions that are not described by the single attribute of photochemical age. However, AM-PM differences in volume growth should be viewed with caution. Much of the discrepancy occurs in the oldest air masses which, as indicated in Fig. 3a and b, have the greatest uncertainty. Organic aerosol concentration shows a smaller AM to PM difference than does total AMS volume.

As an air mass ages, Fig. 4 shows that the number of accumulation mode aerosol particles per ppm CO increases. Estimates for this increase derived from PCASP and DMA observations are in good agreement. At a given photochemical age, AM number concentrations are slightly smaller than in the PM in most but not all cases. Fractional and absolute
Table 2. Ratio of volume to number fractional growth.

\begin{tabular}{lll}
\hline Time & G(AMS V)/G(PCASP N) & G(AMS V)/G(DMA N) \\
\hline AM \& PM & 0.91 & 0.88 \\
AM & 0.52 & 0.34 \\
PM & 0.86 & 1.61 \\
\hline
\end{tabular}

concentration changes for aerosol number and volume have been collected in Table 1. It can be seen that the fractional increase in aerosol volume is, within the scatter of the measurements from different instruments, nearly the same as that for number concentration. A 5-fold increase in volume is accompanied by a 5.5 - fold increase in number. There is more mass (and volume) per $\mathrm{CO}$ in aged air masses because there are more accumulation mode particles. In agreement with this finding, it will be shown in a following section that the average particle size does not increase with photochemical age.

Table 2 provides the ratio of volume (AMS) and number (DMA or PCASP) fractional growth by time period. Ratios are centered on a value of 0.9 with a range from 0.34 to 1.61 depending on time of day and instruments. Fractional increases tend to be sensitive to the low values occurring in young air masses. Examination of the absolute changes provides another perspective. In Table 3 , the ratios of the AMS $\Delta V$ to either the PCASP or DMA $\Delta N$ are given. The $\Delta$ ratios show less variability than the $G$ ratios. We interpret the $\Delta$ ratio as the volume of an average aerosol particle that has been "created" during the aging process. Equivalent diameters $\left(\mathrm{D}_{E Q}\right)$ are given in Table 3. For comparison, Table 3 also includes volume mean diameter, VMD, defined by

$\mathrm{VMD}=(6 V /(\pi N))^{1 / 3}$

where $N$ and $V$ are the total number and volume of accumulation mode particles. Particle diameters determined from the $\Delta$ analysis are comparable to or smaller than VMDs. A mechanistic discussion of particle growth is the topic of a following section.

\subsection{Background concentrations}

The determination of background pollutant levels in the boundary layer over the Mexico City plateau is problematic since even cleaner air masses contain a mixture of aged pollutants well in excess of free tropospheric values. Though there is good day to day ventilation (Fast and Zhong, 1998; de Foy et al., 2006), peak urban concentrations are sufficiently high that just a few percent carry over from one day to the next has an appreciable effect. In K2008, we estimated that background CO was $\sim 130 \mathrm{ppb}$, a value that is the 10th percentile of our urban plume data set. A similar concentration (125 ppb) was measured in the residual layer during the night at Pico de Tres Padres (Herndon et al., 2008). 

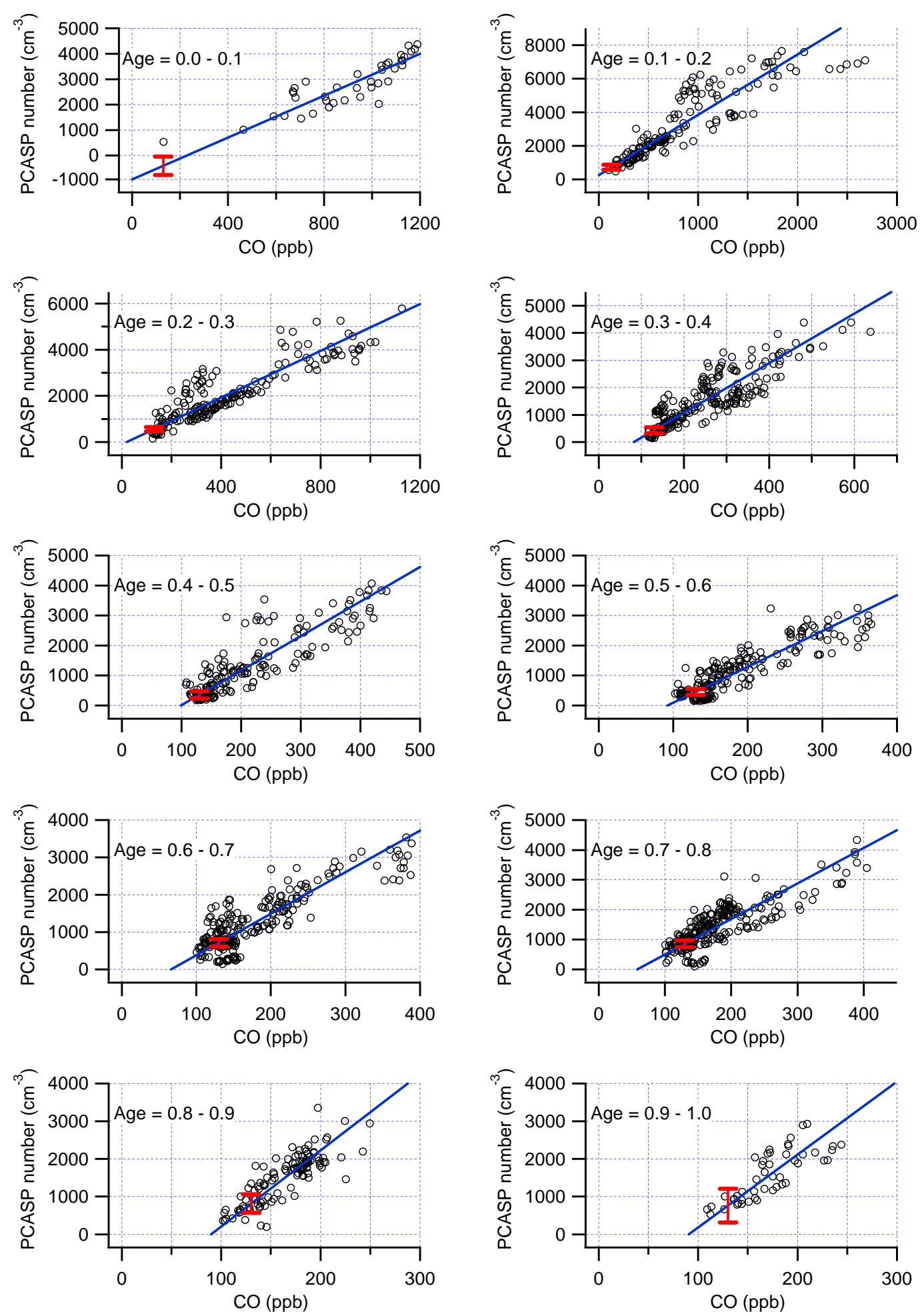

Fig. 5. Scatter plots of PCASP number concentration in the size range $0.1-0.5 \mu \mathrm{m}$ vs. CO concentration. Data set has been split into 10 bins, each spanning 0.1 unit of photochemical age $\left(-\log _{10}\left[\mathrm{NO}_{\mathrm{x}}\right] /\left[\mathrm{NO}_{\mathrm{y}}\right]\right)$ as indicated on plots. Each data point represents a $10 \mathrm{~s}$ measurement period in the urban plume data set. Blue lines are reduced major axis linear least squares regression fits to data points. Slopes are data points in Fig. 4a. Red line shows value and one sigma uncertainty in [Aerosol] at $\mathrm{CO}=130 \mathrm{ppb}$. 
Table 3. Ratio of volume change from AMS to number change from PCASP or DMA due to aging, equivalent diameter, and volume mean diameter.

\begin{tabular}{lllllll}
\hline Time & \multicolumn{3}{c}{ PCASP number } & \multicolumn{3}{c}{ DMA number } \\
\hline & $\Delta V / \Delta N\left(\mu \mathrm{m}^{3}\right)$ & $\mathrm{D}_{E Q}(\mu \mathrm{m})$ & $\mathrm{VMD}^{1}(\mu \mathrm{m})$ & $\Delta V / \Delta N\left(\mu \mathrm{m}^{3}\right)$ & $\mathrm{D}_{\mathrm{EQ}}(\mu \mathrm{m})$ & $\mathrm{VMD}^{1}(\mu \mathrm{m})$ \\
$\mathrm{AM} \& \mathrm{PM}$ & $5.10 \mathrm{e}-3$ & 0.21 & 0.21 & $4.27 \mathrm{e}-3$ & 0.20 & 0.20 \\
$\mathrm{AM}$ & $3.31 \mathrm{e}-3$ & 0.19 & 0.22 & $2.33 \mathrm{e}-3$ & 0.17 & 0.20 \\
$\mathrm{PM}$ & $5.29 \mathrm{e}-3$ & 0.22 & 0.21 & $5.32 \mathrm{e}-3$ & 0.22 & 0.19 \\
\hline
\end{tabular}

1 volume mean diameter $0.1-0.44 \mu \mathrm{m}$

Table 4. Properties of the youngest and oldest AM and PM air masses.

\begin{tabular}{lllllll}
\hline Subset & Photochemical age $^{1}$ & $\mathrm{NO}_{\mathrm{x}} / \mathrm{NO}_{\mathrm{y}}^{2}$ & $\mathrm{CO}(\mathrm{ppb})^{2}$ & $\mathrm{Time}^{2}$ & $\mathrm{DMA}_{p}(\mathrm{Vmax})^{2}(\mu \mathrm{m})$ & $\mathrm{DMA} \mathrm{VMD}^{2}(\mu \mathrm{m})$ \\
\hline AM1 & $0.0-0.2$ & 0.74 & 960 & $10: 54$ & 0.36 & 0.21 \\
AM5 & $0.8-1.0$ & 0.13 & 169 & $11: 26$ & 0.33 & 0.20 \\
PM1 & $0.0-0.2$ & 0.69 & 334 & $13: 45$ & 0.25 & 0.20 \\
PM5 & $0.8-1.0$ & 0.14 & 169 & $16: 08$ & 0.27 & 0.19 \\
\hline
\end{tabular}

1 range

2 average value

Background accumulation mode aerosol concentration have been estimated from the slope and intercept of the regressions in Fig. 5 analogous to the determination of background aerosol mass in K2008. Indicated in red in Fig. 5 are aerosol concentrations at an assumed background condition of $\mathrm{CO}=130 \mathrm{ppb}$. Air masses with background $\mathrm{CO}$ contain an average of 680 particles $\mathrm{cm}^{-3}$ in the size range $0.1-0.5 \mu \mathrm{m}$.

Size distributions shown below are of ambient aerosol consisting of "background" aerosol plus aerosol associated with the urban plume. If background is defined as $130 \mathrm{ppb}$ $\mathrm{CO}$, there is approximately $3 \mu \mathrm{g} \mathrm{m}^{-3}$ of background nonrefractory accumulation mode aerosol, accounting for $15 \%$ of the mass in samples with low photochemical age and $35 \%$ for samples with high photochemical age (K2008). There does not appear to be a viable way of determining the photochemical age dependence of an urban aerosol size distribution independent of the admixture of background air.

\subsection{Size distributions}

Average aerosol size distributions have been determined from the DMA, PCASP, and AMS as a function of photochemical age and time of day. There are significant differences between AM and PM size distributions at equal photochemical age, so composite size distributions from the $\mathrm{AM}+\mathrm{PM}$ are not presented. AM to PM differences are particularly prominent in the Aitken mode number distributions. Smaller effects are visible in the accumulation mode giving rise to the AM-PM differences in volume and number concentration discussed in the previous section. Volume distri- butions from the AM and PM show only minor changes with photochemical age.

Volume size distributions, $d V / d \log D_{p}$, determined from DMA measurements are shown in Fig. 6. Results have been normalized so that the shapes of the distributions can be easily compared. A comparison of AM and PM size distributions shows that the PM distributions have their maximum value at a diameter, denoted $D_{p}(\mathrm{Vmax})$, that is $\sim 50-100 \mathrm{~nm}$ smaller than in the AM. In the PM there is more mass in the Aitken range $(50-100 \mathrm{~nm})$, as compared with AM samples with the same photochemical age. These feature are illustrated explicitly in Fig. 6c, which shows AM and PM samples at a photochemical age of 0.2-0.4. PCASP values for $d V / d \log D_{p}$ are presented in Fig. 7. PM distributions are shifted to smaller size relative to the AM, similar to what was found for the DMA. Neither the PCASP or DMA data set indicates any large changes in volume mean diameter (VMD) with photochemical age.

Size distributions from the AMS have a significantly lower signal to noise ratio than those from the DMA or PCASP and are subject to increased uncertainty because of the conversion from vacuum aerodynamic diameter to geometric diameter and because of size dependent transmission losses. Figure 8 displays the mass size distribution of organic aerosol in the same format used for the DMA and PCASP in Figs. 6 and 7. As with the DMA and PCASP there is not a lot of age variation in $D_{p}(\mathrm{Vmax})$. The same is true for AMS volume (not shown). In contrast to the DMA and PCASP volume measurements, the AM and PM organic size distributions have similar modes diameters. Size distributions of sulfate and 

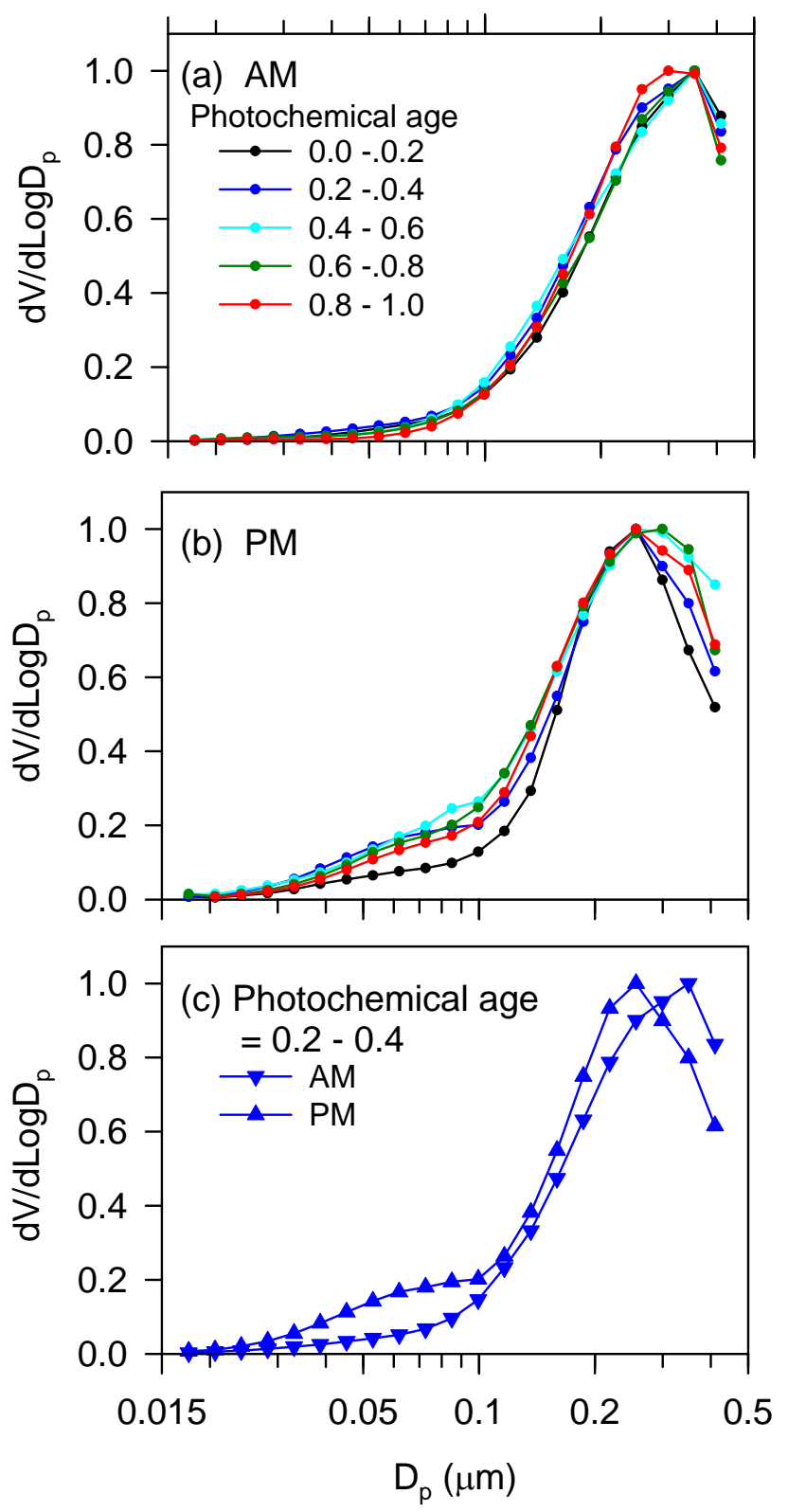

Fig. 6. DMA volume size distributions, $d V / d \log D_{p}$, for (a) $\mathrm{AM}$ and (b) PM portions of urban data set according to photochemical age. In panel (c), AM and PM size distributions are compared for the photochemical age range, $-\log \left(\mathrm{NO}_{\mathrm{x}} / \mathrm{NO}_{\mathrm{y}}\right)$ between 0.2 and 0.4. All size distributions are normalized to have a peak value of one. Before normalization, size distributions differ in magnitude due to dilution and to the addition of condensable species.

nitrate (not shown) have an AM to PM decrease in mode diameter comparable to that seen in the DMA measurements. Because of uncertainties in the AMS size distributions, due in part to the conversion between $\mathrm{D}_{\mathrm{va}}$ and $D_{p}$, our growth law analysis will rely mainly on DMA and PCASP measurements.
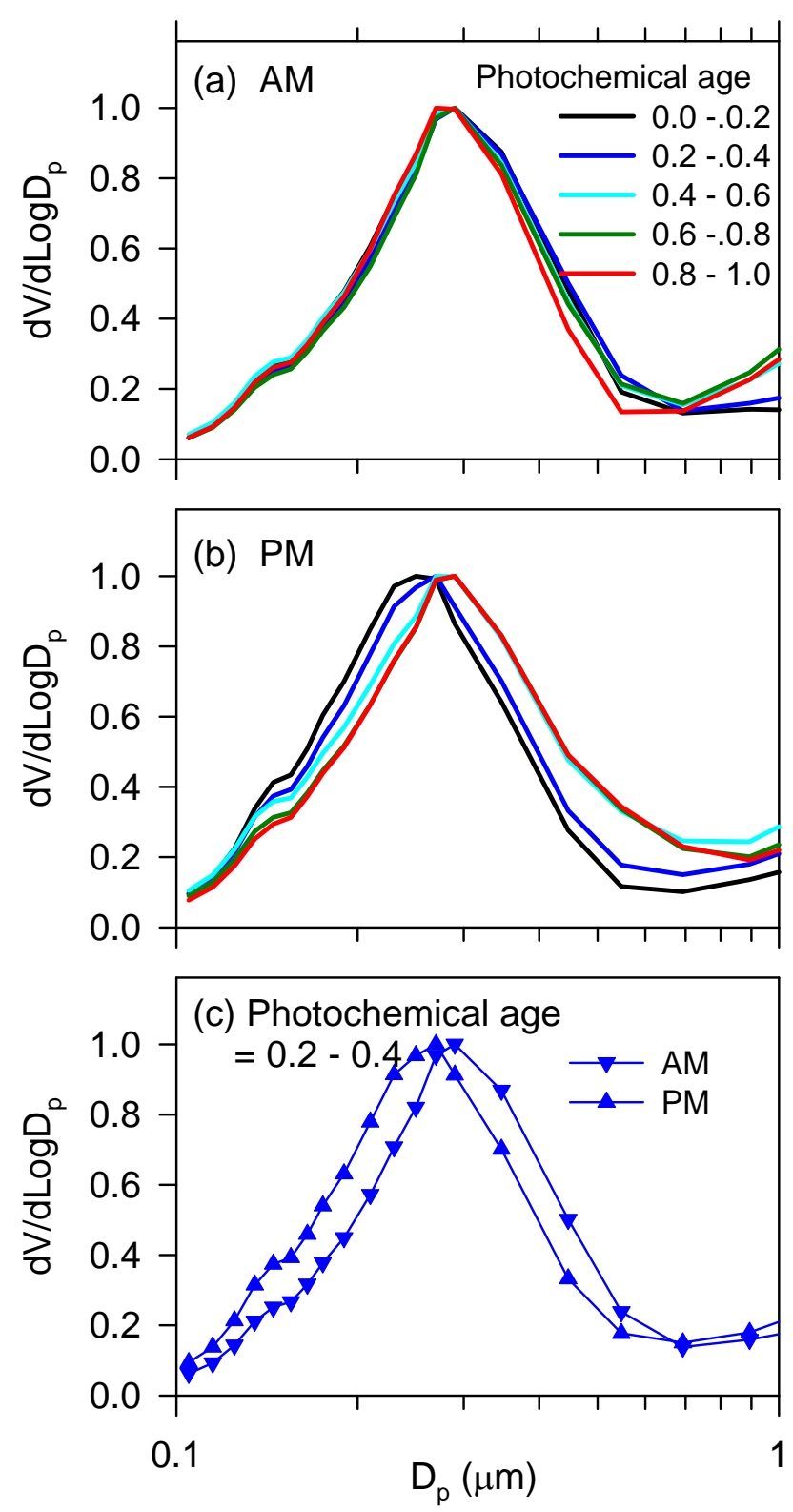

Fig. 7. PCASP volume size distribution, $d V / d \operatorname{LogD}$, for (a) AM and (b) PM portions of urban data set according to photochemical age with an AM-PM comparison in panel (c). Same format as Fig. 6.

Figure 9 shows number distributions, $d \mathrm{~N} / d \log D_{p}$, from the DMA. The format is the same as that used for volume and mass distributions in Figs. 6-8, except that results are not normalized so that absolute differences between distributions can be seen. Number distributions are dominated by the Aitken mode which on average accounts for 80 and $92 \%$ of the total in the AM and PM, respectively. There are twice the total number of particles in the PM as AM, but because of shifts in the distribution shape, the number of accumulation mode particles in the AM and PM is approximately equal. 

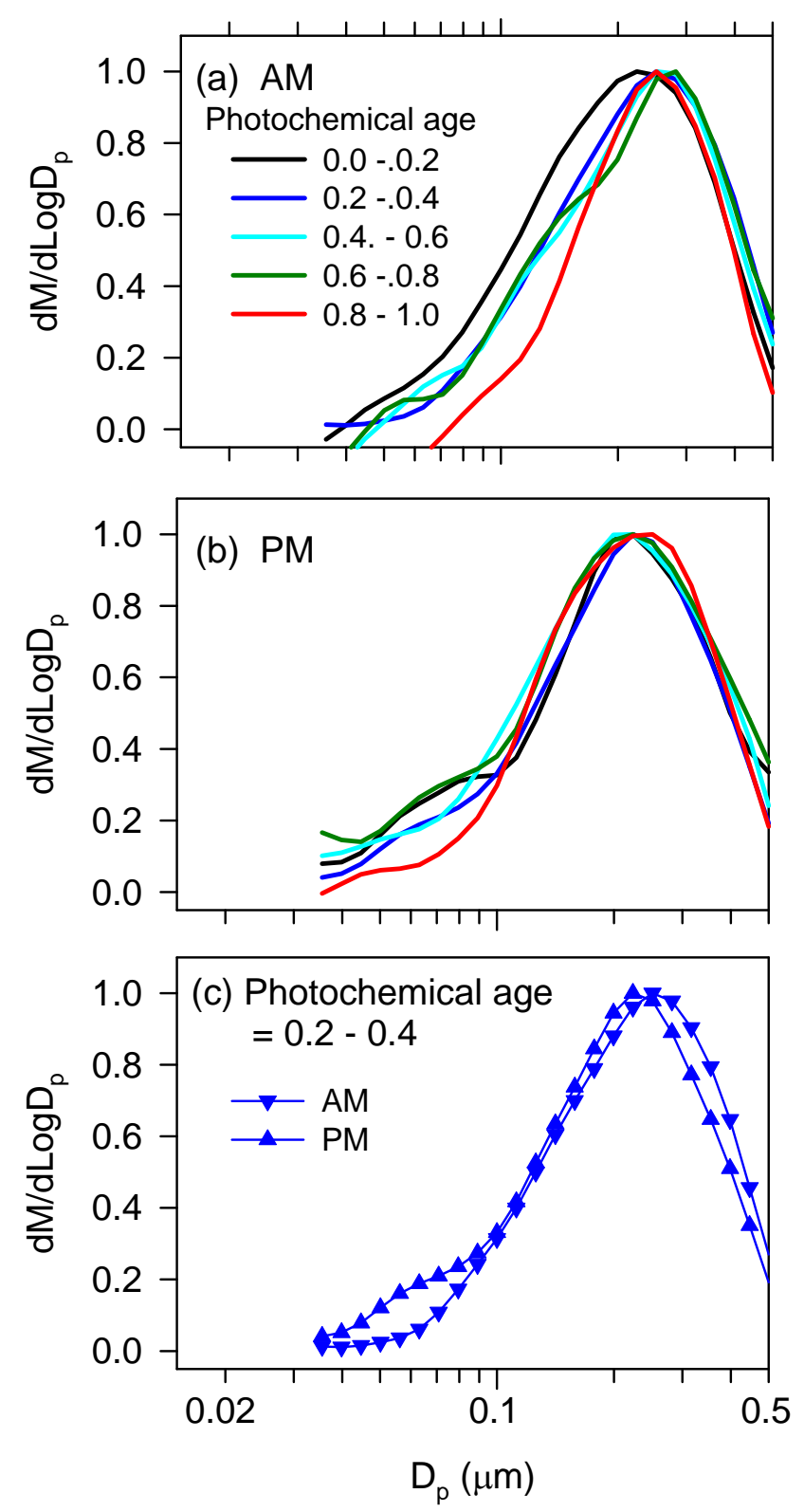

Fig. 8. AMS organic concentration size distribution, $d \mathrm{M} / d \log D_{p}$, for (a) AM and (b) PM portions of urban data set according to photochemical age with an AM-PM comparison in panel (c). Same format as Fig. 6.

A conspicuous difference between AM and PM samples is the greater number of Aitken mode particles in the PM (Fig. 9c). This is a common feature of Mexico City surface DMA measurements where one can follow in time the growth of ultra-fine particles into the tens of $\mathrm{nm}$ size range (Wang, 2006; Iida et al., 2008; Smith et al., 2008). During the time window for the G-1 observations, DMA data from the T0 surface sites indicates an AM (10:00-12:00) to PM (12:00-15:00) increase in number concentration (dominated by the Aitken mode) even though aerosol volume is decreas-
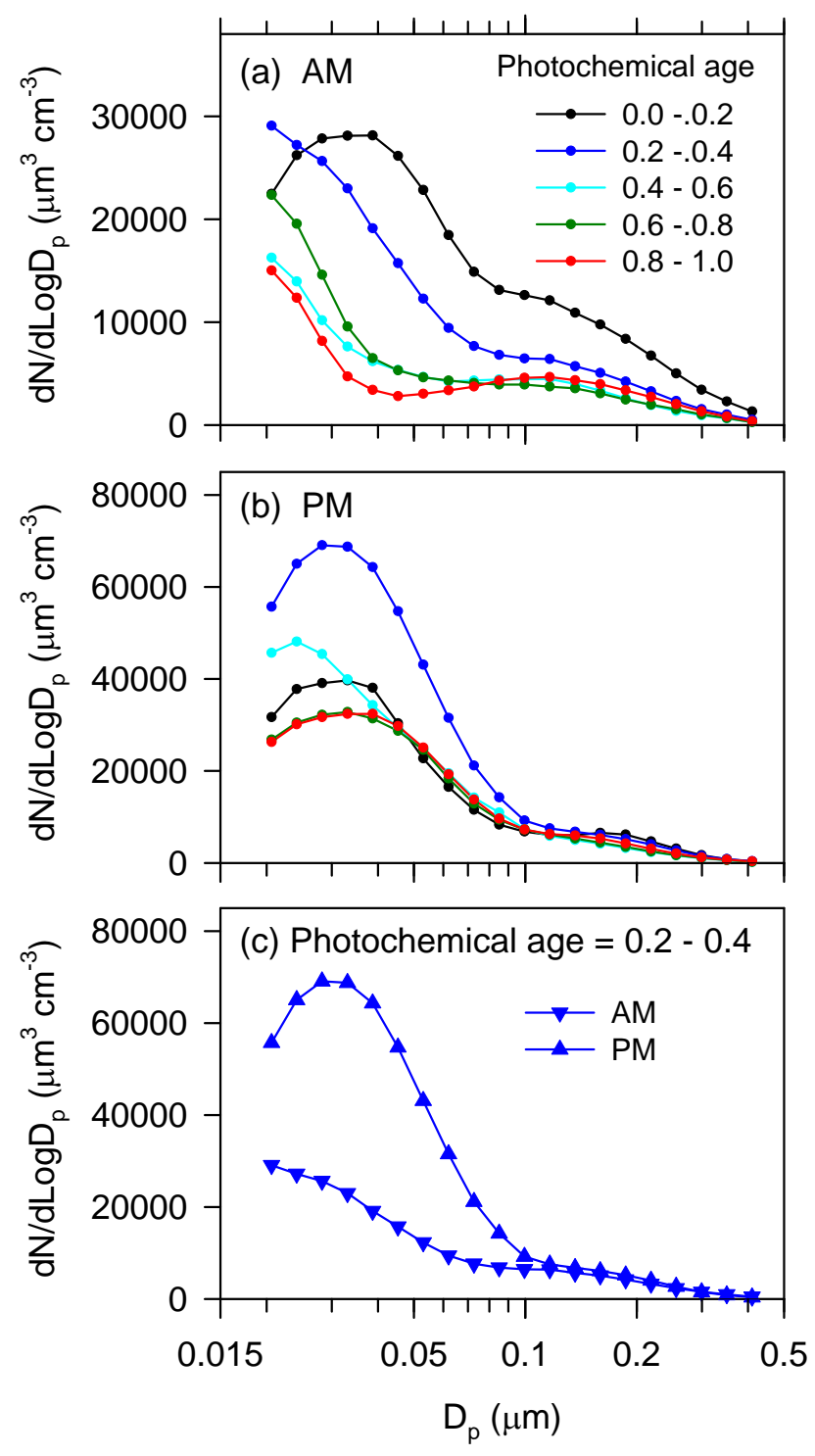

Fig. 9. DMA number size distribution, $d \mathrm{~N} / d \log D_{p}$, for (a) $\mathrm{AM}$ and (b) PM portions of urban data set according to photochemical age with an AM-PM comparison in panel (c). Size distributions have not been normalized.

ing (Wang, 2006). The AM-PM differences for sub $0.1 \mu \mathrm{m}$ aerosol point out that while photochemical age provides a reasonable unidirectional metric for growth of accumulation mode number and volume concentration, it does not provide a complete description of the state of an aerosol. New particle formation and subsequent growth into the Aitken mode depends more on time of day than on photochemical age.

\section{Time sequence}

Properties of the youngest (AM1 and PM1) and oldest (AM5 and PM5) data subsets are presented in Table 4. Differences 
in CO concentration between AM1 and PM1 are in large part due to the rapid increase in boundary layer height that occurs around noon.

Although AM1 will be selected as the initial condition for growth law calculations in a following section, this is not a Lagrangian assignment. There is clearly not enough time for AM1 to grow into AM5. Growth of AM1 into PM5 is possible but would require that much of the aging be accomplished by reactions other than $\mathrm{OH}+\mathrm{NO}_{2}$. Reactive $\mathrm{N}$ measurements on the $\mathrm{C}-130$ indicate that PANs and organic nitrates are important $\mathrm{NO}_{\mathrm{x}}$ oxidation products (Frank Flocke, NCAR, personal communication), which would significantly lessen the time needed to age from $74 \% \mathrm{NO}_{\mathrm{x}}$ to $14 \% \mathrm{NO}_{\mathrm{x}}$. Another possibility is that the precursor to PM5 is an aerosol that looks like AM1 but was emitted hours earlier. Same day photochemistry has been observed to produce a several-fold increase in SOA (Volkamer et al., 2006) which is what is required to explain our observations.

Very rapid chemistry would be required to produce AM5 from an AM1 type aerosol emitted at say, 06:00, in the morning rush hour. This pathway appears unlikely as an analysis of surface observations in Mexico City indicates limited SOA production before 09:00 (Volkamer et al., 2006). If same day growth is not responsible then the precursor to AM5 must be aerosol such as PM1 emitted the previous day or aerosol emitted over night. Night time chemistry could explain the observation from Fig. 3, that the AM growth rates of AMS volume and organic aerosol concentration are lower than the PM growth rates. The chemistry adding aerosol volume, in particular SOA, could slow down at night, while the $\mathrm{NO}_{\mathrm{x}} / \mathrm{NO}_{\mathrm{y}}$ photochemical clock would still be ticking due to $\mathrm{NO}_{3}-\mathrm{N}_{2} \mathrm{O}_{5}$ chemistry.

\section{Aerosol growth}

In this section we consider the partitioning of a semi-volatile compound (called $A$ ) between the gas and liquid aerosol phases. The time evolution of the size distribution of accumulation mode aerosols is determined for the limiting cases of condensation and volume controlled growth.

\subsection{Volume and condensation growth laws}

Calculating the time dependent growth of aerosol particles requires a numerical solution to a set of coupled differential equations (Zhang et al., 2004; Zaveri et al., 2008) that describe gas-phase creation of condensable species (Griffin et al., 2002; Camredon et al., 2007), mass transfer between phases (Wexler and Seinfeld, 1990; Pankow, 2003; Marcolli et al., 2004), thermodynamics of aerosols (Zhang et al., 2000), and chemical reactions on and within aerosols (Maria et al., 2004; Kroll and Seinfeld, 2008). Two categories of growth mechanisms can be distinguished according to whether size distributions reflect the kinetics of mass transfer from the gas to aerosol phase (yielding a condensation growth law) or reflect a thermodynamically favored equilibrium state (yielding many possible growth laws of which condensation and volume growth are 2 limiting cases). Systems will always tend to approach equilibrium but as described by Wexler and Seinfeld (1990) the equilibrium requirement that a species has the same partial pressure above all particles as it has in the gas phase does not always constrain how gas- phase $A$ is to be distributed among particles of different size. Even if there is a unique equilibrium size distribution, the time required to approach it may be longer than other characteristic time scales such as dilution and gas phase oxidation that describe the overall evolution of the gasaerosol system.

For comparison with observed size distributions, we consider volume and condensation growth laws, recognizing that in complicated systems these are limiting cases. Volume growth is defined by

$d V_{p} / d t \sim V_{p}$

or equivalently

$d D_{p} / d t \sim D_{p}$

One instance where Eq. (3) is applicable is the description of equilibrium states reached by a two component system in which both components are miscible in the aerosol phase but only one is volatile. Equation (3) is called a volume growth law because it also describes aerosol growth due to volume dependent reactions such as the oxidation of $\mathrm{SO}_{2}$ to $\mathrm{H}_{2} \mathrm{SO}_{4}$ in cloud droplets. The degree to which Eq. (3) describes growth in realistic non-reactive systems has not been worked out. Phase separation of polar and non-polar compounds would limit the categories of miscible compounds (Song et al., 2007).

Independent of growth law, aerosol growth proceeds by the diffusion of low volatility compounds from the gas to aerosol phase. We consider liquid particles and only allow for the diffusion of species $A$. Equations follow the presentation of Seinfeld and Pandis (SP1998).

The time rate of change of a particle with diameter $D_{p}$, $I_{D}\left(D_{p}\right)$, due to condensation or evaporation is given by (Eq. 12.11, SP1998)

$I_{D}\left(D_{p}, t\right)$

$=d D_{p} / d t=4 D_{A} M_{A} /\left(R T D_{p} \rho_{p}\right) f(\mathrm{Kn}, \alpha)\left(p_{A}-p_{\mathrm{eq}, A}\right)$

where $D_{A}$ is the diffusivity of species $A$ in air, $M_{A}$ is its molecular weight, $R$ is the ideal gas law constant, $T$ is temperature, and $\rho_{p}$ particle density. The driving force for condensation is the difference between the equilibrium pressure of species $A$ at the particles surface, $p_{\mathrm{eq}, A}$, and its pressure far from the particle, $p_{A} . f(\mathrm{Kn}, \alpha)$ is a transition regime factor that interpolates between the kinetic and continuum 
regimes. The Fuchs and Sutugin form of $f$ is given by (Eq. 11.43, SP1998):

$f(\mathrm{Kn}, \alpha)=0.75 \alpha(1+\mathrm{Kn}) /\left(\mathrm{Kn}^{2}+\mathrm{Kn}+0.283 \mathrm{Kn} \alpha+0.75 \alpha\right)$

where $\alpha$ is an accommodation factor that expresses the probability that a collision of molecule of $A$ with a particle leads to uptake. The Knudsen number, Kn, is

$\mathrm{Kn}=2 \lambda / D_{p}$

where $\lambda$ is the mean free path of the condensable species in air. In a population of particles described by a size distribution $n_{D}\left(D_{p}, t\right)=d N / d D_{p}$, the time evolution due to gasphase condensation is given by (Eq. 12.10, SP1998).

$\partial n_{D}\left(D_{p}, t\right) / \partial t+\partial\left[I_{D}\left(D_{p}, t\right) n_{D}\left(D_{p}, t\right)\right] / \partial D_{p}=0$

If condensed phase $A$ is a solid or is non-volatile, $p_{\mathrm{eq}, A}$ is constant and in the latter case equal to zero. The solution of Eqs. (4-7), neglecting gas-phase transfer of other species, then yields a condensation growth law in which the distribution of $A$ among different size particles is determined by mass transfer rates from the gas to aerosol phase. For small particles, in the kinetic regime, $\mathrm{Kn} \gg 1$ and $d D_{p} / d t$ is independent of particle size. For larger particles, in the continuum regime, $\mathrm{Kn} \ll 1$ and $d D_{p} / d t$ is proportional to $1 / D_{p}$. The fractional change in volume with time is $\left(d V_{p} / d t\right) / V_{p}$ which will be proportional to $1 / D_{p}$ in the kinetic regime and $1 / D_{p}^{2}$ in the continuum regime. Under condensation growth conditions, smaller particles thus grow faster in diameter than larger ones resulting in a size distribution that becomes narrower with time. For accumulation mode aerosol at concentrations typical of Mexico City, the time constant, $\tau_{g}$, for the gas phase to approach equilibrium with the aerosol phase is generally of the order of seconds to minutes (Wexler and Seinfeld, 1990).

In the case of a volatile solute, $p_{\mathrm{eq}, A}$ varies with time as the concentration of $A$ in the aerosol phase changes. Given an equilibrium relation between gas phase and condensed phase $A$, such as supplied by absorptive-partitioning theory (Pankow, 1994), the solution of Eqs. (4-7) will distribute $A$ among different size particles such that the partial pressures are the same. The resulting growth law will, in general, be different than condensation growth as it incorporates thermodynamic constraints. A volume growth law is one possibility among many. A realistic solution for a multi-component aerosol requires additional coupled equations as the condensation of $A$ will be accompanied by the transfer of other volatile species and $\mathrm{H}_{2} \mathrm{O}$ between particles.

The approach to equilibrium is characterized by two time constants; $\tau_{g}$, as above and a second time scale $\tau_{l}$, which describes the equilibration among different size particles accomplished by diffusive transport of semi-volatile material. Marcolli et al. (2004) show that in a closed system, $\tau_{l} \sim D_{p}^{2} / p_{0, A}$, where $p_{0, A}$ is the equilibrium vapor pressure of pure A. Marcolli et al. (2004) point out that for organic semivolatile compounds of atmospheric relevance, $p_{0}$ (and hence $\tau_{l}$ ) varies by over 10 orders of magnitude and that functionality and molecular weight will determine whether equilibrium is reached in a given time period. For high molecular weight, multi-functional compounds, $\tau_{l}$ can be days or longer. If $\tau_{l}$ is much greater than the aerosol age, the aerosol would retain a kinetically determined condensation size distribution. Another way of retaining the condensation size distribution is to have aerosol-phase reactions produce lessvolatile compounds on a time scale that competes with $\tau_{l}$. Aerosol phase oligimorization reactions are known to yield high molecular weight products with greatly reduced vapor pressures (Kalberer et al., 2004). As ambient aerosol contains a mixture of compounds with a range of volatilities, it is unlikely that full equilibrium is reached across the whole aerosol population.

\subsection{Calculated changes in aerosol size distribution}

Growth calculations are used to determine the time evolution of the size distribution of accumulation mode aerosols. A low photochemical age size distribution is taken as an initial condition. In the calculations, aerosols accrete material and evolve in time by either a condensation or a volume growth mechanism till their total volume has increased by an amount commensurate with the growth data presented above. There are two objectives to this exercise. First, to determine the consequences of idealized mechanisms on size distribution. Second, to determine if these calculations yield a size distribution that resembles that observed in high photochemical age aerosols. Of particular interest is the observation that a 5fold increase in per $\mathrm{CO}$ aerosol volume with photochemical age is achieved by increasing the number of accumulation mode particles while keeping their average size about constant.

There are many caveats to the growth calculations. We treat only gas to particle conversion of a single condensable substance. Particles are assumed to be internally mixed. Coarse (super micrometer particles) are neglected. Differences between the size distributions measured at low RH and at ambient RH though likely small are not taken into account. Omitted from the calculations are processes such as nucleation, primary aerosol emissions, and coagulation that determine the abundance and evolution of the smaller aerosol particles. Mixing between air parcels is ignored and background aerosol is considered only as an adjustment factor to relate per $\mathrm{CO}$ changes in aerosol volume to changes in background containing ambient aerosol concentration.

In the condensation calculations it is assumed that $p_{\text {eq, } A}=0$, so gas-phase uptake is irreversible. For specificity, the condensable species has a molecular weight of 100 , a diffusivity of $10^{-1} \mathrm{~cm}^{2} \mathrm{~s}^{-1}$, and $\alpha=0.01$. Depending on initial size distribution and the amount of growth, the mode diameter of $d V / d \log D_{p}$ can increase or decrease. In a volume 

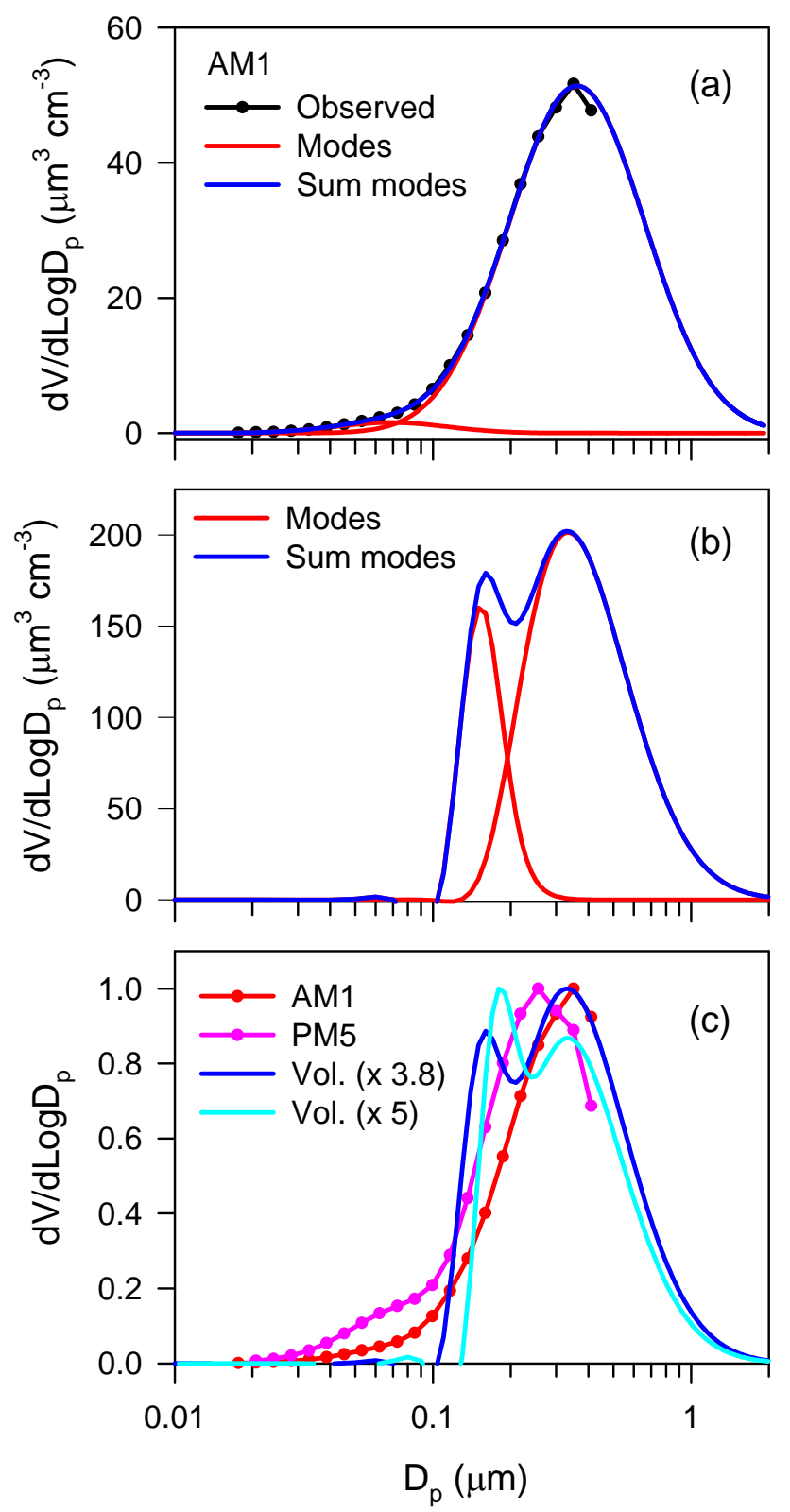

Fig. 10. Volume size distributions showing effects of condensation growth. (a) Observed young DMA sample (AM1) and a two log normal fit. (b) Fitted log normals after volume of AM1 has increased by a factor of 3.8 by condensation growth mechanism. (c) Observed DMA samples (AM1 and PM5) compared with calculated size distribution after AM1 has grown by a factor of 3.8 and 5. Peak heights normalized to unity.

controlled reaction, addition of mass shifts the size distribution to larger sizes but preserves the shape of $d V_{p} / d \log D_{p}$ vs. $\log D_{p}$.

Figures 10 and 11 show $d V_{p} / d \log D_{p}$ calculated according to condensation and volume growth mechanisms, respectively. The initial size distribution is from a low photochemical age sample, AM1 (Table 4). Final aerosol volumes are

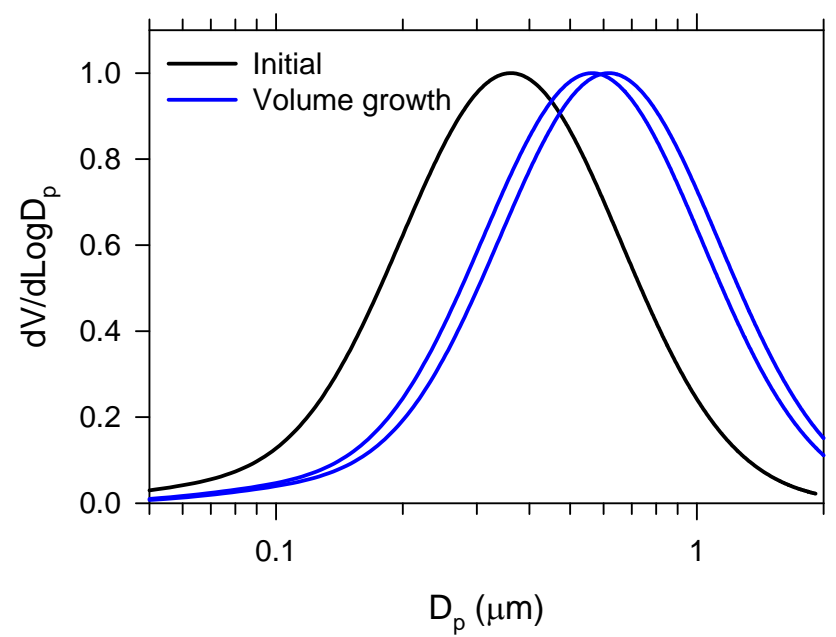

Fig. 11. An initial volume size distribution and size distributions that result from a 3.8 and 5 fold increase in volume by a volume growth mechanism. Size distributions are normalized to have the same peak height. The initial distribution is a 2 component log normal fit to the DMA AM1 (see Fig. 10a). The peak of $d V / d \log D_{p}$ is initially at $D_{p}=0.36 \mu \mathrm{m}$ and increases to 0.57 and $0.62 \mu \mathrm{m}$ after growth. The fractional increase in $D_{p}$ is $3.8^{1 / 3}$ and $5^{1 / 3}$, respectively.

3.8 and 5 times the initial volume. A factor of 5 is the AMS aerosol volume growth factor given in Table 1 (rounded up from 4.9) and refers to changes in plume aerosol normalized to $\mathrm{CO}$. We estimate that there is $3 \mu \mathrm{g} \mathrm{m}^{-3}$ of background aerosol in the initial and final states, constituting 15 and $35 \%$ of the total aerosol, respectively. If background aerosol does not change, the growth experienced by the background containing total size distribution should be $5(0.65 / 0.85)=3.8$. Results are presented for both a 3.8 and 5.0 - fold increase in volume.

To illustrate the growth process, an initial size distribution is represented by two log normals corresponding to Aitken and accumulation modes (Fig. 10a). Initially the Aitken mode has very little mass but, as can be seen from Fig. 9a, most of the number concentration. Figure 10b shows the two $\log$ normals and their sum at the point where condensation has increased the total volume by a factor of 3.8. In Fig. 10c, the initial and an aged PM size distribution are compared with calculated values after the volume has increased by factors of 3.8 and 5. The later size distributions are normalized to have the same peak value which obscures the fact that, except at small $D_{p}$, the value of $d V / d \log D_{p}$ after growth is greater than the initial value. For our conditions most of the growth occurs in the accumulation mode which narrows but retains a peak at a diameter close to the initial peak. Percentage wise, the largest change is in the Aitken mode which grows from $2.4 \%$ to $23 \%$ and $28 \%$ of the total volume after an overall growth of a factor of 3.8 and 5, respectively. The peak of the Aitken mode shifts $80-100 \mathrm{~nm}$ to larger size at 
Table 5. Changes in accumulation mode aerosol from unprocessed to aged samples (AM1 to PM5) with a comparison to condensation and growth calculations.

\begin{tabular}{llll}
\hline Parameter & Observed $^{1}$ & Condensation growth $^{2}$ & Volume growth $^{2}$ \\
\hline $\mathrm{N}\left(\mathrm{cm}^{-3}\right)^{3}$ & $5.9^{4}$ & $5.3(5.3)^{5}$ & $1.0(1.0)^{6}$ \\
$D_{p}(\mu \mathrm{m})$ at peak of $d V / d \log D_{p}$ & $-0.11^{7}$ & $-0.03(-0.14)^{5}$ & $0.20(0.26)^{6}$ \\
$\mathrm{VMD}(\mu \mathrm{m})$ & $-0.006^{8}$ & $-0.009(0.02)^{9}$ & $0.11(0.15)^{9}$ \\
\hline
\end{tabular}

1 Observed data from DMA. All results for size range $0.1-0.44 \mu \mathrm{m}$.

2 Volume increased by a factor of 3.8 or, in parenthesis, 5.0.

3 Change in number concentration, $N$, expressed as a factor relative to AM1.

4 Similar to Table 1 which gives change for $\mathrm{AM}+\mathrm{PM}$ data set.

5 From $d V / d \log D_{p}$ in Fig. 10c.

6 From $d V / d \log D_{p}$ in Fig. 11.

7 Fig. 6a and b.

8 Table 4.

9 Fig. 12.

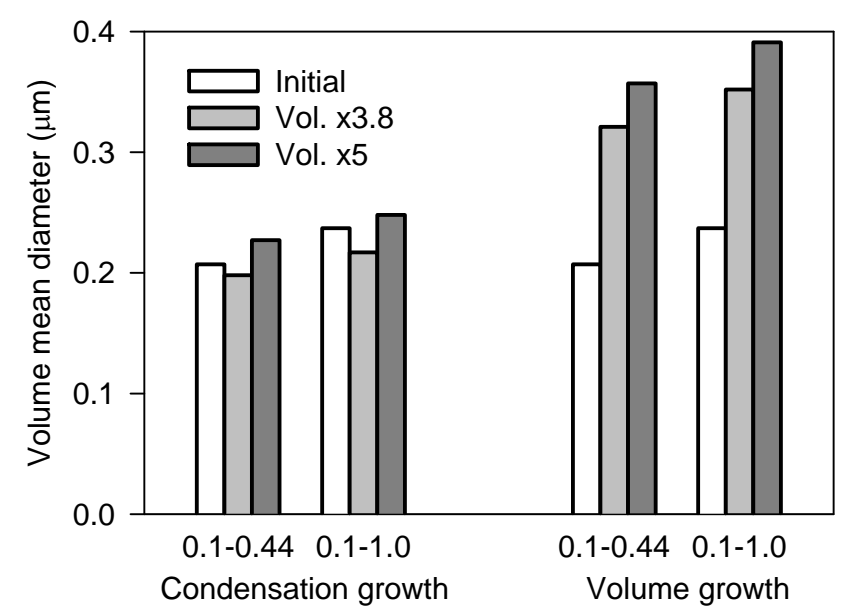

Fig. 12. Volume mean diameter of initial aerosol and that produced after a 3.8 and 5 fold increase in volume by either a condensation or volume growth mechanism. VMD is calculated over 2 size ranges: $0.1-0.44 \mu \mathrm{m}$ and $0.1-1.0 \mu \mathrm{m}$.

which point there is significant overlap with the accumulation mode, giving rise to a double peak size distribution different from what is actually observed in high photochemical age aerosol. After growth by condensation, the small diameter side of the accumulation mode is almost a step function. The later and probably the former feature can be traced back to the simplicity of our calculation. Nevertheless, condensation growth reproduces the main feature of the aging process; namely that increased volume is caused by more accumulation mode particles, not larger particles, and that a final state is reached that resembles observed aged aerosol.

A volume growth mechanism, illustrated in Fig. 11, yields a size distribution shifted to much larger $D_{p}$ than can be supported by our measurements. This feature is further illus- trated in Fig. 12 which shows that condensation growth only slightly changes average particle size (VMD), which is to be contrasted with the larger VMDs produced by a volume growth mechanism.

\section{Discussion}

\subsection{Growth mechanism}

Consideration of time sequences in Sect. 5 gives weight to the hypothesis that the older PM aerosol samples (i.e., PM5) evolved from minimally processed aerosol emitted earlier the same day (i.e., AM1). The formation pathway for aged aerosol sampled in the AM is ambiguous. Precursors could be aerosol emitted the previous day (entrained from the residual layer into the growing AM boundary layer), overnight, or early in the morning. Because of this ambiguity we will focus on the transformations that lead to the aged aerosol observed in mid to late afternoon. A summary of observed and predicted growth characteristics is contained in Table 5. Based on the criteria of number concentration and particle diameter, the growth from AM1 to PM5 appears to be more like that expected from a condensation growth mechanism than a volume growth mechanism. Because organics constitute more than $60 \%$ of the non-refractory accumulation mode volume, the growth characteristics deduced from volume measurements should strongly reflect the organic component.

The growth of Aitken mode particles into the accumulation mode size range, such as occurs in the condensation mechanism (Fig. 10b), provides an explanation for the observation that the addition of aerosol volume with age is accompanied by an increase in particle number concentration. In the young AM1 and PM1 data subsets, particles smaller than 
$0.1 \mu \mathrm{m}$ make up 80 and $88 \%$ of the total number concentration. If during condensation growth these particles all reach accumulation mode size $\left(D_{p}>0.1 \mu \mathrm{m}\right)$ then the total number of accumulation mode particles increases by a factor of 5 or 8 - comparable to what is calculated from Fig. 4. Average particle size (VMD) in the accumulation mode remains nearly constant due to an influx of small particles from the Aitken mode coupled with lower growth rates for large particles.

Because of missing physics, the above estimates of the change in accumulation mode particles with age are only qualitative. Condensation calculations are performed without regard to other processes, most notably creation of ultrafine particles, emissions, and dilution with background air. As a consequence, particles smaller than $0.1 \mu \mathrm{m}$ are calculated to be completely removed, whereas in reality sub $0.1 \mu \mathrm{m}$ particles always dominate the number distribution. In order for this to happen, an air mass that is aging and becoming dilute as it is advected away from its major source of pollutants must receive a continued supply of ultrafine or Aitken size particles from nucleation events, downwind emission sources, or from background air. It is also possible that inclusion of new particle formation, emissions, mixing, and coagulation would smear out the double peak structure of the accumulation mode yielding a single peak as observed.

Growth calculations do not take into account the chemical complexity of Mexico City aerosol. The chemically uniform initial aerosol should be replaced with a multi-component, multi-phase mixture which need not be internally mixed. Condensing species include $\mathrm{H}_{2} \mathrm{SO}_{4}, \mathrm{NH}_{3}, \mathrm{HNO}_{3}$, and a spectrum of VOCs with different volatilities (Robinson et al., 2007). Detailed calculations which would yield equilibrium states and the time constants for reaching equilibrium are required to set a priori bounds on possible growth behaviors but that is beyond the scope of this study and in any event is made difficult by uncertainties in the properties of the organic aerosol phase as well as gas-phase precursors and subsequent aerosol-phase chemistry. A determination of the partitioning behavior of VOCs based on a full-physics model would be especially useful as it would tell how the absence of a volume growth peak constrains aerosol chemical properties.

Changes in aerosol composition with age (K2008) indicate that growth of aerosol nitrate in older samples has stopped, consistent with a re-partitioning of $\mathrm{HNO}_{3}$ and $\mathrm{NH}_{3}$ back into the gas phase under less polluted conditions. Organic aerosol per CO (Fig. 3b), in contrast, continues to increase up to the oldest photochemical age. Although individual organic species could be evaporating and others condensing, there is no evidence of net organic aerosol evaporation over a time span of $\sim 1 / 2$ to 1 day, which could be due to most SOA being composed of low volatility compounds either directly absorbed from the gas phase (Robinson et al., 2004; Camredon et al; 2007) or chemically formed in the aerosol phase by e.g. oligomerization reaction (Kalberer et al., 2004).

\subsection{Comparisons with other studies}

A comparison of calculated size distributions in Fig. 10 with observations by Brock et al. (2008) is instructive because their observations correspond more closely to conditions in the condensation calculation than does Mexico City. Brock et al. (2008) report observed aerosol size distributions in air masses that had been cut off from fresh emissions by being advected in an elevated layer over the Atlantic Ocean. Since the principal chemical transformation after one days travel time is gas phase oxidation of $\mathrm{SO}_{2}$ producing aerosol sulfate, it is likely that the observed aerosol size distribution presented in their Fig. $4 \mathrm{c}$ and e are the result of a condensation growth mechanism such as used to construct Fig. 10. In common with our calculations, the Brock et al. (2008) observations indicate 1) the nearly complete removal of sub $0.1 \mu \mathrm{m}$ aerosol and 2) a minimal shift in $D_{p}(\mathrm{Vmax})$ with age. Also, at the $40 \mathrm{~h}$ mid-point of their pseudo Lagrangian observations, aerosol within the nominal accumulation mode size range of $0.1-1.0 \mu \mathrm{m}$ show two volume peaks at $\sim 0.2$ and $0.4 \mu \mathrm{m}$ similar to the calculated distribution in Fig. 10b and c. Even though the condensation calculations presented here are more appropriate for the isolated air masses observed by Brock et al. (2008), there are features that we expect to remain valid in the more complicated Mexico City environment. It is expected that a more realistic condensation model would still predict an increase in accumulation mode particles due to growth of the Aitken mode and would still not produce the much larger particles generated from a volume growth mechanism.

In Pittsburg (Zhang et al., 2005) and Tokyo (Miyakawa et al., 2008), two regions in which accumulation mode aerosol is dominated by organics and sulfate, AMS size distributions have been published that suggest that aerosol growth follows a condensation growth law. Evidence from Pittsburgh is that the size distributions of sulfate and SOA are always similar and that the mode diameter of $d M / d \log D_{p}$ does not change much with time of day. During one period in which intense new particle formation was observed in the morning, it was found that the size-resolved increase of SOA later in the day closely followed a condensation sink determined from observed aerosol surface area. Evidence from Tokyo consists of size distributions of fresh and aged aerosol. These differ at the small end of the accumulation mode but are virtually identical at the large end where one would expect to see a larger mode in the aged samples if volume growth occurred.

The eventual fate of $\mathrm{OA}$ is an open question. While our measurements show persistence for at least $1 / 2$ day, surface measurements of aerosol phase water soluble organic carbon and nitrate at the T1 site have been interpreted as indicating OA evaporation on a similar time scale (Hennigan et al., 2008). At least one smog chamber study has shown reversible formation of $\mathrm{OA}$, in that case from $\alpha$ pinene oxidation products (Greishop et al, 2007). Such studies are limited: Kroll et al. (2007) note that "the reversibility of SOA 
formation over long time scales is highly uncertain (experimental studies are largely lacking at present)".

\section{Conclusions}

As in our previous study of aerosol growth in the Mexico City urban plume (K2008), the time evolution of aerosol properties has been determined by 1) defining an urban data set, 2) splitting the urban data set into subsets according to photochemical age, and 3) for each subset performing a linear regression of the aerosol property vs. CO. Regression slopes yield the volume, mass, or number concentration of aerosol per ppm of urban $\mathrm{CO}$ above background. When these slopes are plotted as a function of photochemical age they portray the changes in aerosol volume, mass, or number that occur during photochemical aging.

PCASP, DMA, and AMS measurements indicate that the amount of photochemical aging that changes the $\mathrm{NO}_{\mathrm{x}} / \mathrm{NO}_{\mathrm{y}}$ ratio from $\sim 80 \%$ to $12 \%$, roughly estimated as requiring $1 / 2$ to 1 day atmospheric processing, is accompanied by a 5-fold increase in aerosol volume per CO. Similar calculations for accumulation mode number concentration yield a 5.5 - fold increase. These observations show that the increase in volume with age is due to more accumulation mode particles (per CO) in older air masses - not due to larger particles. In support of this conclusion, volume mean diameters, determined from PCASP and DMA size distributions do not increase between fresh emissions and aged air masses.

On average more than $60 \%$ of the non-refractory accumulation mode volume consisted of organic species, so trends in aerosol volume should be strongly influenced by SOA formation. A more than proportionate share of the aerosol volume increase is due to organic constituents which increase in mass by a factor of 6.4 .

Having established that aerosol volume growth is due to increased numbers of accumulation mode particles, number and volume size distributions were examined to provide information on the growth process. As expected, number concentration is dominated by the Aitken mode and sub micrometer volume by the accumulation mode. For a given photochemical age, the aerosol number concentration in the Aitken mode was larger in the afternoon than in morning. Surface observations from T0 show particles growing into the 10's of nm size range in the afternoon, not tied to age changes. While photochemical age does account for volume growth in the accumulation mode, numbers of ultra-fine and Aitken mode particles appear to depend more on time of day.

Volume size distributions showed some changes between the morning and afternoon, with the afternoon samples generally having peak values of $d V / d \log D_{p}$ at smaller $D_{p}$ than in the morning. Within the AM or PM subsets, $d V / d \log D_{p}$ showed little variation with photochemical age. These observations pertain also to $d M$ (organic) $/ d \log D_{p}$. Although the growth behavior of organics in a mixed aerosol is our main concern, our analysis relied primarily on DMA and PCASP size distributions as surrogates because of a greater signal to noise ratio.

Age related changes in aerosol size distributions were calculated for two limiting mechanisms leading to condensation and volume growth laws. In the first case, the rate of accretion of low volatility material into the aerosol phase is determined by size dependent rates of mass transfer. The second case is usually reserved for the creation of aerosol mass from volume dependent reactions but can also result as an equilibrium state. A low photochemical age size distribution is taken as an initial condition and the calculations are stopped when the accumulation mode aerosol volume increases by a factor of 3.8 or 5, the former figure derived from an approximate way of taking into account a non-growing background aerosol.

Condensation calculations reproduce the main features of the observed volume size distribution: A 5-fold increase in volume with age is caused by a nearly equal increase in accumulation mode particles. A two log normal representation of the growing aerosol shows that the increase in accumulation mode number concentration is due to growth of Aitken mode particles into the accumulation mode size range $\left(D_{p}>0.1 \mu \mathrm{m}\right)$. Only a slight change in volume mean diameter accompanies a 5-fold volume growth as the size increase of larger particles is counteracted by the addition of "new" small accumulation mode particles. This process also leaves the mode size of $d V / d \log D_{p}$ nearly unchanged. Volume controlled growth, in contrast, produces a size distribution shifted to a larger diameter, distinctly different from what is observed.

Condensation growth laws have been typically applied to describe aerosol formation from nearly non-volatile $\mathrm{H}_{2} \mathrm{SO}_{4}$. By extension, one could suppose that the condensation-like growth seen in the Mexico City urban plume implies a preponderance of low volatility species and since organics constitute more than $60 \%$ of the volume, low volatility organic constituents. Low volatility organics could be either formed in the gas phase or created in aerosol phase reactions. Supporting evidence for this hypothesis is that the organic to $\mathrm{CO}$ ratio shows no signs of decreasing as older aerosol is advected into cleaner air which would favor evaporation of more volatile species.

We have presented condensation and volume growth laws as limiting cases with poorly defined domains of validity and have pointed out the approximations in our growth law calculations. One approximation is that we are treating a single condensing species, where as in reality aerosols have multiple species. Condensation of a single species will in general cause other species including $\mathrm{H}_{2} \mathrm{O}$ to redistribute among different size particles so that the equilibrium condition of equal partial pressure of a substance above each particle, identical to that in the gas phase, is achieved. Although mass transport of semi-volatile species between the gas and aerosol phase has been extensively studied (see Seinfeld and Pandis, 1998 
and references therein), the time evolution of a population of aerosol particles is not readily determined because it depends on the physical properties and interactions of multiple compounds, many of which are poorly characterized organic species. Multi-component sensitivity calculations are needed to determine how the absence of a volume growth mode constrains the properties of poorly characterized organic aerosol components.

Acknowledgements. We thank chief pilot Bob Hannigan and the flight crew from PNNL for a job well done. We gratefully acknowledge the Atmospheric Science Program within the Office of Biological and Environmental Research of DOE for supporting field and analysis activities and for providing the G-1 aircraft. Use of a PTR-MS provided by EMSL is appreciated. Discussions with Ernie Lewis (BNL) on aerosol growth were very helpful. We thank Donna Sueper (Aerodyne and Univ. CO) for her assistance in reducing the AMS data. This research was performed under sponsorship of the US DOE under contracts DE-AC02-98CH10886.

Edited by: S. Madronich

\section{References}

Albrecht, B.: Aerosols, cloud microphysics, and fractional cloudiness, Science, 245, 1227-1230, 1989.

Bowman, F. K., Odum, J. R., Seinfeld, J. H., and Pandis, S. N.: Mathematical model for gas-particle partitioning of secondary organic aerosols, Atmos. Environ., 31, 3921-3931, 1997.

Brock, C. A., Washenfelder, R. A., Trainer, M., et al.: Particle growth in the plumes of coal-fired power plants, J. Geophys. Res., 107, 4155, doi:10.1029/2001JD001062, 2002.

Brock, C. A., Sullivan, A. P., Peltier, R. E., et al.: Sources of particulate matter in the northeastern United States in summer: 2. Evolution of chemical and microphysical properties, J. Geophys. Res., 113, D08302, doi:10.1029/2007JD009241, 2008.

Camredon, M., Aumont, B., Lee-Taylor, J., and Madronich, S.: The SOA/VOC/NOx system: an explicit model of secondary organic aerosol formation, Atmos. Chem. Phys., 7, 5599-5610, 2007, http://www.atmos-chem-phys.net/7/5599/2007/.

DeCarlo, P. F., Dunlea, E. J., Kimmel, J. R., et al.: Fast airborne aerosol size and chemistry measurements above Mexico City and Central Mexico during the MILAGRO campaign, Atmos. Chem. Phys., 8, 4027-4048, 2008,

http://www.atmos-chem-phys.net/8/4027/2008/.

de Foy, B., Varela, J. R., Molina, L. T., and Molina, M. J.: Rapid ventilation of the Mexico City basin and regional fate of the urban plume, Atmos. Chem. Phys., 6, 2321-2335, 2006, http://www.atmos-chem-phys.net/6/2321/2006/.

Doran, J. C., Barnard, J. C., Arnott, W. P., et al.: The T1-T2 study: evolution of aerosol properties downwind of Mexico City, Atmos. Chem. Phys., 7, 1585-1598, 2007, http://www.atmos-chem-phys.net/7/1585/2007/.

Drewnick, F., Hings, S. S., DeCarlo, P., Jayne, J. T., Gonin, M., Fuhrer, K., Weimer, S., Jimenez, J. L., Demerjian, K. L., Borrmann, S., and Worsnop, D. R.: A new time-of-flight Aerosol Mass Spectrometer (TOF-AMS) - Instrument Description and first field deployment, Aerosol Sci. Tech., 39, 637-658, 2005.
Fast, J. D. and Zhong, S.: Meteorological factors associated with inhomogeneous ozone concentrations within the Mexico City basin, J. Geophys. Res., 103(D15), 18927-18946, 1998.

Greishop, A. P., Donahue, N. M., and Robinson, A. L.: Is the gas-phase partitioning in alpha-pinene secondary organic aerosol reversible? Geophys. Res. Lett., 34, L14810, doi:10.1029/2007GL029987, 2007.

Griffin, R. J., Dabdub, D., and Seinfeld, J. H.: Secondary organic aerosol 1. Atmospheric chemical mechanism for production of molecular constituents, J. Geophys. Res., 107, 4332, doi:10.1029/2001JD000541, 2002.

Hennigan, C. J., Sullivan, A. P., Fountoukis, C. I., Nenes, A., Hecobian, A., Vargas, I., Peltier, R. E., Case Hanks, A. T., Huey, L. G., Lefer, B. L., Russell, A. G., and Weber, R. J.: On the volatility and production mechanisms of newly formed nitrate and water soluble organic aerosol in Mexico City, Atmos. Chem. Phys., 8, 3761-3768, 2008, http://www.atmos-chem-phys.net/8/3761/2008/.

Herndon, S. C., Onasch, T. B., Wood, E. C., et al.: The correlation of secondary organic aerosol with odd oxygen in Mexico City, Geophys. Res. Lett., 35, L15804, doi:10.1029/2008GL034058, 2008.

Iida, K., Stolzenburg, M. R., McMurry, P. H.., and Smith, J. N.: Estimating nanoparticle growth rates from sizedependent charged fractions: Analysis of new particle formation events in Mexico City, J. Geophys. Res., 113, D05207, doi:10.1029/2007JD009260, 2008.

Jaenicke, R.: Atmospheric aerosols and global climate, J. Aerosol Sci., 11, 577-588, 1980.

Kalberer, M., Paulson, D., Sax, M., Steinbacher, M., Dommen, J., Prevot, A. S. H., Fisseha, R., Weingartner, E., Frankevich, V., Zenobi, R., and Baltensperger, U.: Identification of polymers as major components of atmospheric organic aerosols, Science, 303, 1659-1662, 2004.

Kleinman, L. I., Daum, P. H., Lee, Y.-N., Senum, G. I., Springston, S. R., Wang, J., Berkowitz, C., Hubbe, J., Zaveri, R. A., Brechtel, F. J., Jayne, J., Onasch, T. B., and Worsnop, D.: Aircraft observations of aerosol composition and ageing in New England and Mid-Atlantic States during the summer 2002 New England Air Quality Study field campaign, J. Geophys. Res., 112, D09310, doi:10.1029/2006JD007786, 2007.

Kleinman, L. I., Springston, S. R., Daum, P. H., Lee, Y.-N., Nunnermacker, L. J., Senum, G. I., Wang, J., Weinstein-Lloyd, J., Alexander, M. L., Hubbe, J., Ortega, J., Canagaratna, M. R., and Jayne, J.: The time evolution of aerosol composition over the Mexico City plateau, Atmos. Chem. Phys., 8, 1559-1575, 2008, http://www.atmos-chem-phys.net/8/1559/2008/.

Kroll, J. H., Chan, A. W. H., Ng, N. L., Flagan, R. C., and Seinfeld, J. H.: Reactions of semivolatile organics and their effects on secondary organic aerosol formation, Environ. Sci. Technol., 41, 3545-3550, 2007.

Kroll, J. H. and Seinfeld, J. H.: Chemistry of secondary organic aerosol: Formation and evolution of low-volatility organics in the atmosphere, Atmos. Environ., 42, 3593-3624, 2008.

Liu, P. S. K., Deng, R., Smith, K. A., Williams, L. R., Jayne, J. T., Canagaratna, M. R., Moore, K., Onasch, T. B., Worsnop, D. R., and Deshler, T. : Transmission efficiency of an aerodynamic focusing lens system: Comparison of model calculations and laboratory measurements for the aerodyne aerosol Mass Spectrom- 
eter, Aerosol Sci. Technol., 41, 721-733, 2007.

Maria, S. F., Russell, L. M., Gilles, M. K., and Myneni, S. C. B.: Organic aerosol growth mechanisms and their climate-forcing implications, Science, 306, 1921-1924, 2004.

Marcolli, C., Luo, B. P., Peter, T., and Wienhold, F. G.: Internal mixing of the organic aerosol by gas phase diffusion of semivolatile organic compounds, Atmos. Chem. Phys., 4, 25932599, 2004, http://www.atmos-chem-phys.net/4/2593/2004/.

McMurry, P. H., Rader, D. J., and Stith, J. L.: Studies of aerosol formation in power plant plumes - I. Growth laws for secondary aerosols in power plant plumes: Implications for chemical conversion mechanisms, Atmos. Environ., 15, 2315-2327, 1981.

Miyakawa, T., Takegawa, N., and Kondo, Y.: Photochemical evolution of submicron aerosol chemical composition in the Tokyo megacity region in summer, J. Geophys. Res., 113, D14304, doi:10.1029/2007JD009493, 2008.

Molina, L. T., Madronich, S., Gaffney, J. S., and Singh, H. B.: Overview of MILAGRO/INTEX-B campaign, in IGACtivities Newsletter of the International Global Atmospheric Chemistry Project, 38, 2-15, April 2008.

Nunnermacker, L. J., Weinstein-Lloyd, J., Hillery, B., Giebel, B., Kleinman, L. I., Springston, S. R., Daum, P. H., Gaffney, J., Marley, N., and Huey, G.: Aircraft and ground-based measurements of hydroperoxides during the 2006 MILAGRO field campaign, Atmos. Chem. Phys., 8, 7619-7636, 2008, http://www.atmos-chem-phys.net/8/7619/2008/.

Odum, J. R., Hoffmann, T., Bowman, F., Collins, D., and Seinfeld, J. H.: Gas/particle partitioning and secondary organic aerosol yields, Environ. Sci. Technol., 30, 2580-2585, 1996.

Pankow, J. F.: An absorption model of gas/particle partitioning of organic compounds in the atmosphere, Atmos. Environ., 28, 185-188, 1994.

Pankow, J. F.: Gas/particle partitioning of neutral and ionizing compounds to single and multi-phase particles. 1. United modeling framework, Atmos. Environ., 37, 3323-3333, 2003.

Press, W. H., Flannery, B. P., Teukolsky, S. A., and Vetterling, W. T.: Numerical Recipes, The Art of Scientific Computing, Cambridge University Press, p. 507, 1986.

Robinson, A. L., Donahue, N. M., Shrivastava, M. K., Weitkamp, E. A., Sage, A. M., Greishop, A. P., Lane, T. E., Pierce, J. R., and Pandis, S. N.: Rethinking organic aerosol: Semivolatile emissions and photochemical aging, Science, 315, 1259-1262, 2007.

Rogers, R. R., Hair, J. W., Hoestetler, C. A., et al.: NASA LaRC airborne high spectral resolution lidar aerosol measurements during MILAGRO: observations and validation, Atmos. Chem. Phys. Discuss., 9, 8817-8856, 2009,

http://www.atmos-chem-phys-discuss.net/9/8817/2009/.

Seinfeld, J. H., and Pandis, S. N.: Atmospheric Chemistry and Physics, From Air Pollution to Climate Change, ISBN 0-47117816-0, John Wiley \& Sons, 1998.

Schwartz, S. E.: The whitehouse effect - Shortwave radiate forcing of climate by anthropogenic aerosol: An overview, J. Aerosol. Sci., 27, 359-382, 1996.
Smith, J. N., Dunn, M. J., VanRecken, T. M., Iida, K., Stolzenburg, M. R., McMurry, P. H., and Huey, L. G.: Chemical composition of atmospheric nanoparticles formed from nucleation in Tecamac, Mexico: Evidence for an important role for organic species in nanoparticle growth, Geophys. Res. Lett., 35, L04808, doi:10.1029/2007GL032523, 2008.

Song C., Zaveri, R. A., Alexander, M. L., Thornton, J. A., Madronich, S., Ortega, J. V., Zelenyuk, A., Yu, X.-Y., Laskin, A., and Maughan, D.: Effect of hydrophobic primary organic aerosol on secondary organic aerosol formation from ozonolysis of a-pinene, Geophysical Research Letters, 34, L20803, doi:10.1029/2007GL030720, 2007.

Twomey, S. A.: Pollution and the planetary albedo, Atmos. Environ., 8, 1251-1256, 1974.

Volkamer, R., Jimenez, J. L., San Martini, F., Dzepina, K., Zhang, Q., Salcedo, D., Molina, L. T., Worsnop, D. R., and Molina, M. J.: Secondary organic aerosol formation from anthropogenic air pollution: Rapid and higher than expected, Geophys. Res. Lett., 33, L17811, doi:10.1029/2006GL026899, 2006.

Wang, J.: Aerosol size distribution and CCN spectrum observed at T0 site during MILAGRO, DOE Atmospheric Science Program meeting, Boulder, CO, USA, October 25-27, 2006.

Wang, J., Collins, D., Covert, D., Elleman, R., Ferrare, R. A., Gasparini, R., Jonsson, H., Ogren, J., Sheridan, P., and Tsay, S.-C.: Temporal variation of aerosol properties at a rural continental site and study of aerosol evolution through growth law analysis, J. Geophys. Res., 111, D18203, doi:10.1029/2005JD006704, 2006.

Wexler, A. S. and Seinfeld, J. H.: The distribution of ammonium salts among a size and composition dispersed aerosol, Atmos. Environ., 24A, 1231-1246, 1990.

Zaveri, R. A., Zaveri, R., Alexander, L., Ortega, J., et al.: Evolution of Trace Gases and Aerosols in the Mexico City Pollution Outflow during a Long Range Transport Event, Proceedings of the 27th Annual Conference of the American Association for Aerosol Research, Orlando, FL, USA, October 20-24, 2008.

Zaveri, R. A., Easter, R. C., Fast, J. D., and Peters, L. K.: Model for Simulating Aerosol Interactions and Chemistry (MOSAIC), J. Geophys. Res., 113, D13204, doi:10.1029/2007JD008782, 2008.

Zhang, Q., Worsnop, D. R., Canagaratna, M. R., and Jimenez, J. L.: Hydrocarbon-like and oxygenated organic aerosols in Pittsburgh: Insights into sources and processes of organic aerosols, Atmos. Chem. Phys., 5, 3289-3311, 2005, http://www.atmos-chem-phys.net/5/3289/2005/.

Zhang, Y., Seigneur, C., Seinfeld, J. H., Jacobson, M., Clegg, S. L., and Binkowski, F. S.: A comparative review of inorganic aerosol thermodynamic equilibrium modules: Similarities, differences, and their likely causes, Atmos. Environ., 34, 117-137, 2000.

Zhang, Y., Pun, B., Vijayaraghavan, K., Wu, S.-Y., Seigneur, C., Pandis, S. N., Jacobson, M. Z., Nenes, A., and Seinfeld, J. H.: Development and application of the Model of Aerosol Dynamics, Reaction, ionization, and Dissolution (MADRID), J. Geophys. Res., 109, D01202, doi:10.1029/2003JD003501, 2004. 